\title{
Determination of snowmaking efficiency on a ski slope from observations and modelling of snowmaking events and seasonal snow accumulation
}

\author{
Pierre Spandre $^{1,2}$, Hugues François ${ }^{1}$, Emmanuel Thibert $^{1}$, Samuel Morin $^{2}$, and Emmanuelle George-Marcelpoil ${ }^{1}$ \\ ${ }^{1}$ Université Grenoble Alpes, Irstea, Grenoble \\ ${ }^{2}$ Météo-France-CNRS, CNRM UMR 3589, Centre d'Etudes de la Neige, Grenoble
}

Correspondence to: Pierre Spandre (pierre.spandre@ irstea.fr)

Received: 12 August 2016 - Discussion started: 5 September 2016

Revised: 14 February 2017 - Accepted: 6 March 2017 - Published: 7 April 2017

\begin{abstract}
The production of Machine Made (MM) snow is now generalized in ski resorts and represents the most common method of adaptation for mitigating the impact of a lack of snow on skiing. Most investigations of correlations between snow conditions and the ski industry's economy focus on the production of MM snow though not one of these has taken into account the efficiency of the snowmaking process. The present study consists of observations of snow conditions (depth and mass) using a Differential GPS method and snow density coring, following snowmaking events and seasonal snow accumulation in Les Deux Alpes ski resort (French Alps). A detailed physically based snowpack model accounting for grooming and snowmaking was used to compute the seasonal evolution of the snowpack and compared to the observations. Our results show that approximately $30 \%$ of the water mass can be recovered as MM snow within $10 \mathrm{~m}$ from the center of a MM snow pile after production and $50 \%$ within $20 \mathrm{~m}$. Observations and simulations on the ski slope were relatively consistent with $60 \%( \pm 10 \%)$ of the water mass used for snowmaking within the limits of the ski slope. Losses due to thermodynamic effects were estimated in the current case example to be less than $10 \%$ of the total water mass. These results suggest that even in ideal conditions for production a significant fraction of the water used for snowmaking can not be found as MM snow within the limits of the ski slope with most of the missing fraction of water. This is due to site dependent characteristics (e.g. meteorological conditions, topography).
\end{abstract}

\section{Introduction}

Snow is essential for the ski industry (Fauve et al., 2002). It encourages ski lift operators to increase the amount of grooming and snowmaking methods so as to lessen their dependency on the variability of snow conditions. (Durand et al., 2009; Hughes and Robinson, 1996). Snowmaking has been the main concern of recent investigations concerning the impact of climate change on the ski industry (Scott et al., 2003; Hennessy et al., 2007; Steiger, 2010; Pütz et al., 2011; Damm et al., 2014). To the best of our knowledge however, none of these results accounted for the efficiency of the snowmaking process i.e. the actual conversion of water volumes used for the production of Machine Made (MM, Fierz et al., 2009) snow on ski slopes. Related water losses may be significant (Eisel et al., 1990; Spandre et al., 2016b).

Water losses during snowmaking were addressed in a few studies with different approaches and investigated factors. Eisel et al. (1988) estimated consumptive water loss through evaporation and sublimation during the snowmaking process through a combination of nine field experiments (mass balance) and a theoretical approach (energy balance). They found an average of $6 \%$ water loss and a negative linear relationship between the atmospheric temperature and water loss. Hanzer et al. (2014) implemented the relationship derived by Eisel et al. (1988) in a detailed snowpack model and found that for typical snowmaking conditions, water losses due to evaporation and sublimation ranged between 2 and $13 \%$. Eisel et al. (1990) later showed that water loss during snowmaking could not be limited to evaporation and sublimation alone. This was done though the comparison of 
Table 1. Dates of the field campaign carried out during the 2015-2016 winter season. "MM snow Obs." and "Ski slope Obs." correspond respectively to dates when observations were performed on MM snow piles and ski slope.

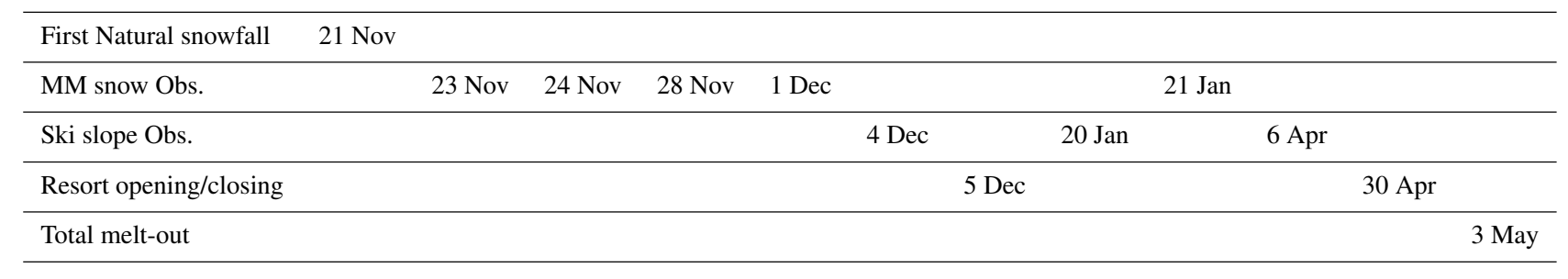

runoffs simulated by a hydrological model with observations in six test sites in Colorado ski areas. An additional 7 to $33 \%$ loss was deduced after the initial loss (related to evaporation and sublimation), resulting in a total consumptive loss of 13 to $37 \%$. Recently, Olefs et al. (2010) reported from interviews with professionals that water losses due to evaporation, sublimation and wind erosion were estimated as being between 15 to $40 \%$ for air-water guns and 5 to $15 \%$ for fan guns. Spandre et al. (2016b) performed observations on four ski slopes and found a minimum water loss of over $25 \%$ with significant differences between observation sites (some exceeding $50 \%$ ). He concluded that external factors (wind, topography, vegetation) probably had a significant impact on the efficiency of MM snow production.

The present study aims to provide a detailed description of the seasonal evolution of a ski slope snowpack in operational conditions with a high spatial resolution $(0.5 \mathrm{~m}$ grid), including the additional MM snow from snowmaking methods. Equivalent water masses of MM snow piles were measured prior to any action by the grooming machines, and both snow depth (SD) and snow water equivalent (SWE) of the prepared ski slope were observed on several occasions. These observations were crossed with all available data on snow production (water flow, temperature, wind) and with the results of simulations using a detailed physically based snowpack model (Spandre et al., 2016b). This was done so as to compute the ratio of MM snow mass on the ski slope through snowmaking with respect to the water mass used for the production of MM snow (ratio defined as the Water Recovery Rate, WRR). The method is described in the first section, and includes all measurements and tests set up to characterize uncertainties related to our measurements. The retained uncertainties and the results of observations as a result of these tests are detailed in a second section and discussed.

\section{Material and methods}

\subsection{Description of observations: study area}

The "Coolidge" ski slope is a beginner's trail near Les 2 Alpes ski resort, a village (Oisans range, French Alps) at an elevation of $1680 \mathrm{~m}$ a.s.l. The area is mainly a west-facing and almost flat slope $\left(\approx 5^{\circ}\right)$. It is an important slope in the resort used for skiing lessons and as a route back down to the village on skis, obliging technical services to keep it under operational condition for skiing from the opening of the resort (early December) to its closure (late April). Two distinct series of observations were carried out on this site during the 2015-2016 winter season (Table 1):

- Volume measurements of single snowmaking events and the related mass. Five production sessions were observed (Table 1).

- Seasonal snow accumulation measurements of snow depth (SD) and snow water equivalent (SWE) on the prepared ski slope i.e. in the skiing conditions as offered to skiers. Three observations were carried out (Table 1).

A single air/water gun was used for our observations. The professional snowmakers of Les 2 Alpes kindly provided all available data regarding the production of MM snow on the study site. This covers 15 min time step records of the water flow of the snowgun $\left(\mathrm{m}^{3} \mathrm{~h}^{-1}\right)$, the wet-bulb temperature $\left({ }^{\circ} \mathrm{C}\right)$, the wind speed $\left(\mathrm{m} \mathrm{s}^{-1}\right)$ and direction ( ${ }^{\circ}$ from North) measured in the vicinity of the study area. These data were used both as inputs to force the snowpack model (water flow, amount of MM snow) and as references for the analysis of the outputs of the model (same variables, wet-bulb temperature). The data also helped the characterization of the production conditions (wet-bulb temperature and wind conditions). Based on communications with the snowgun manufacturer, the uncertainty of water volumes used for snowmaking was neglected (below $1 \%$ according to the manufacturer).

The study area was defined as being based on the local topography and the initial surface of the ski slope. The Coolidge ski slope is wide (up to $75 \mathrm{~m}$ from January to March). It is a relatively flat grass covered area. In such a case defining limits to the ski slope can be tricky and quite subjective. In order to be as objective as possible and consistent throughout the season we defined the following rules which were systematically applied:

- All MM snow piles were measured on the total surface where MM snow was observed, unless a major obstacle (a tree, a building) stood in the area, bypassed by us.

- The surface of the operational ski slope defined by the ski patrollers changed during the ski season by a fac- 


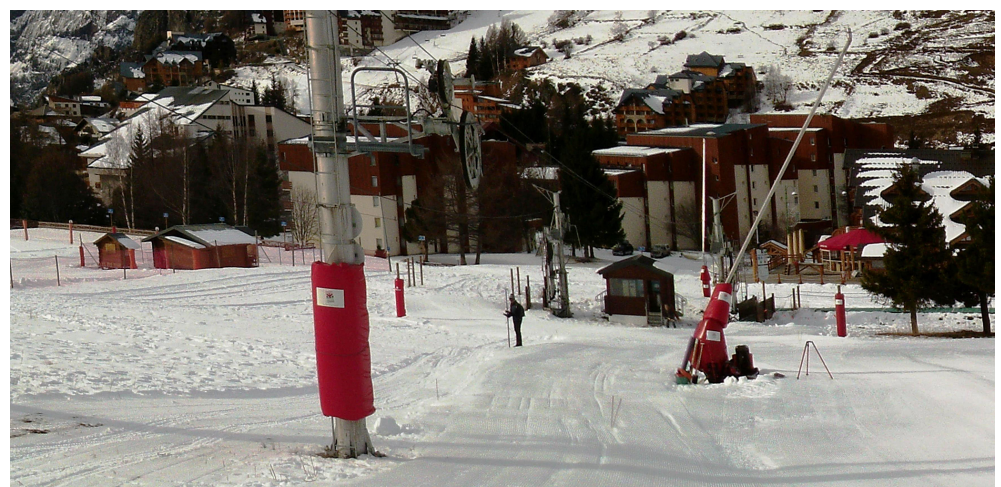

Figure 1. The Coolidge ski slope conditions on 4 December 2015, the day before the resort opened. Edges with unprepared areas and obstacles (trees, lift infrastructures, snowgun) of the ski slope can clearly be seen.

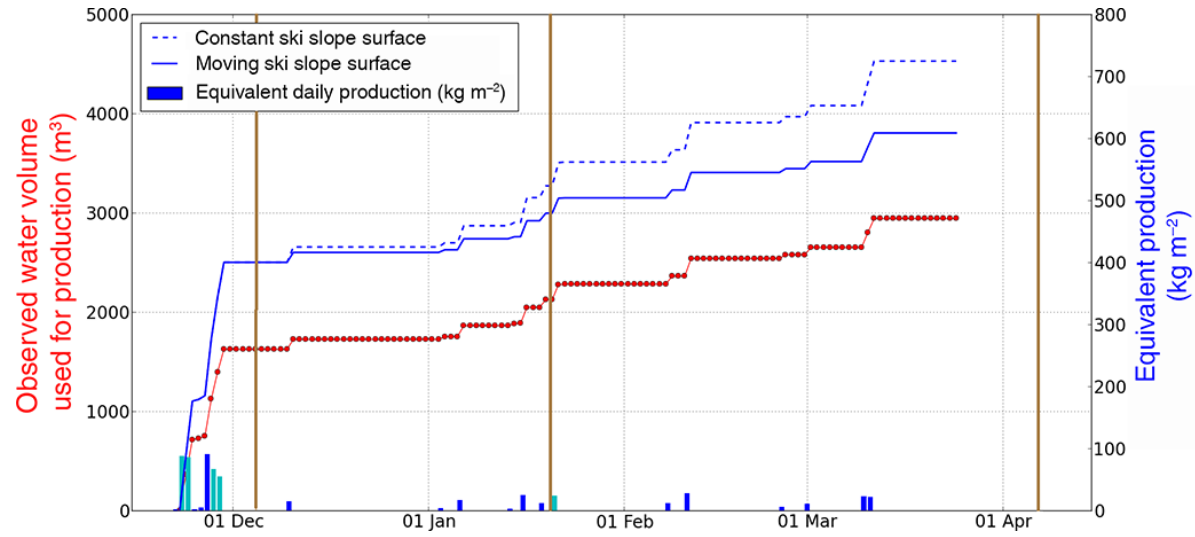

Figure 2. Observed water volumes used for production (red) and the equivalent mass on the ski slope surface (blue). Bars stand for the daily production (bottom). Production sessions when observations were performed on MM snow piles (cyan bars) and dates when ski slope observations were carried out (light brown) are outlined.

tor of up to 1.75 , depending on snow conditions. The ski slope was wider in January $\left(6632 \mathrm{~m}^{2}\right)$ and April $\left(7067 \mathrm{~m}^{2}\right)$ than on 4 December $\left(4063 \mathrm{~m}^{2}\right)$ since there was very little natural snow at this time. This also made the edge easier to identify (Fig. 1). On 20 January and 6 April we collected data across the total of the marked out ski slopes even though the study area for SD and SWE calculations was consistently limited to the area defined by the edge on 4 December 2015 in order to provide comparable data. A sensitivity test of the SD and SWE concerning the study surface was conducted by considering an offset of $\pm 2 \mathrm{~m}$ from the edge. The impact on SD and SWE was computed and discussed.

- The surface considered to calculate the MM snow production rate in the model was defined as the total marked out ski slope area: the "useful" area (Fig. 2). Beyond the initial MM snow production (late November) natural snowfall occurred and the ski slope was enlarged. The enlarged area was thereafter defined as the spreading area for MM snow.
The relationship between the average snow depth (Sect. 2) and the study surface (defined by the 4 December 2015 edge) was explored through the comparison of the calculated snow depth within the study area $\left(4063 \mathrm{~m}^{2}\right)$ and buffered surfaces of $\pm 2 \mathrm{~m}$ from the edge of the study area (3425 and $4749 \mathrm{~m}^{2}$ respectively). Differences between a buffered snow depth and a snow depth calculated for the study area are consistent over the three observation sessions (data not shown). The larger the surface i.e. the further the edge from the snowgun, the smaller the average snow depth. The average difference is +0.03 and $-0.03 \mathrm{~m}$ for the smaller $(-2 \mathrm{~m})$ and larger $(+2 \mathrm{~m})$ areas respectively, showing little variation from one observation session to another (5\% relative difference maximum). This suggests that the surroundings of the study area undergo consistent evolutions throughout the season and that to address the evolution of the snowpack from initial observation the most important thing to do is to follow the exact same area. This tends to confirm that the MM snow produced after 4 December 2015 was in fact spread over the total usable surface after the slope was enlarged. 


\subsection{Snow depth measurement method and related uncertainties}

\subsubsection{Snow surface elevation point measurements}

Snow surface elevation was measured on several occasions (Table 1) thanks to a geodetic double frequency Differential GNSS (GPS + GLONASS) Leica GS10 high precision receiver. A permanent frame was set up close to the study area on 17 November 2015 in order to provide a positioning antenna carrier at the reference station. The position of the GPS antenna once mounted on this frame was post processed to obtain the absolute position of the reference station within a few centimeters. To measure points coordinates in the investigated area, we used a rover receiver operating in real time kinematics (RTK) from the reference station. Specific points were defined (painted dots on concrete ground) and systematically re-measured during each GPS session as a control. The baseline (reference-to-rover) was less than $500 \mathrm{~m}$ for every single session which ensures a relative position from the reference station with a spatial (3-D) accuracy below $0.02 \mathrm{~m}$. The intrinsic uncertainty on the $Z$ (altitudinal) position of the Differential GPS was $0.012 \mathrm{~m}$ for all of the observation sessions. The average density of points concerning the measurement of the elevation of the MM snow piles surface was $11.1 \mathrm{~m}^{2}$ per point $\left( \pm 3.3 \mathrm{~m}^{2}\right.$ per point $)$ i.e. each point covered a surface equivalent to a $1.88 \mathrm{~m}$ radius disk $( \pm 0.3 \mathrm{~m})$. The average density for the measurement of the elevation of the ski slope surface was $16.4 \mathrm{~m}^{2}$ per point $\left( \pm 4.4 \mathrm{~m}^{2}\right.$ per point $)$ i.e. each point covered a surface equivalent to a $2.29 \mathrm{~m}$ radius disk $( \pm 0.31 \mathrm{~m})$. The point density was adapted to the local conditions (terrain complexity), for each session i.e. the larger the changes in the snow surface, the more points were taken. This explains why the average surface per point concerning the measurement of the elevation of the ski slope surface (when snow surface is equalized by grooming machines) is larger than that of MM snow piles.

The bare ground surface elevation was also measured on 17 November 2015 in order to be compared with the snowfree helicopter-borne laser scan Digital Elevation Model (DEM) of the area acquired in November 2015. Before checking the elevation consistency between our GPS survey and this snow-free DEM, we adjusted $(-0.0032 \mathrm{~m})$ the elevation of our reference station on a local common levelling control point ( $800 \mathrm{~m}$ apart) provided by Institut Géographique National (IGN).

\subsubsection{Interpolation on a regular grid}

In order to compare snow surface elevations with each other or with the DEM on the bare ground, data need to be interpolated on a regular grid. The existing snow-free DEM had a spatial resolution of $0.5 \mathrm{~m}\left(0.25 \mathrm{~m}^{2}\right.$ pixels $)$ which we nominated as the working grid. All data were interpolated on this grid thanks to a preliminary Triangular Irregular Network
(TIN) method with a Delaunay natural neighbour triangulation (Maune, 2007). The same method was used to treat all observation sessions. Once interpolated on the working grid, all observation sessions could be compared to each other or with the bare ground, providing a spatial observation of the snow depth across the study area.

Such a method implies several sources of uncertainty (instrument, interpolation) which we intended to assess through three distinct tests:

- a high-resolution Terrestrial Laser Scan (TLS, Prokop, 2008) was used on 1 December 2015 on a MM snow pile which we also measured with the GPS method. We were then able to compare the differences on both the GPS points alone and the interpolated GPS points with the TLS points in order to obtain the error that arises when interpolation is executed (effect of point density).

- Differences with the DEM of the bare ground of both the GPS points alone and the interpolated points of the bare ground by the GPS method (17 November 2015) were calculated.

- Hand made snow depth measurements were made on three occasions (observations of the ski slope) with a probe and compared with the interpolated snow depth by the GPS method.

\subsubsection{Evaluation of uncertainties on snow depth}

First of all we compared the interpolated snow surface elevations with data from a Terrestrial Laser Scan (see Appendix $\mathrm{B}$ for more details). An average elevation difference of $-0.012 \mathrm{~m}$ was measured between the interpolated GPS and the TLS snow surfaces $\left(2018 \mathrm{~m}^{2}\right.$ ). The Root Mean Square of the differences (RMSD) was $0.055 \mathrm{~m}$ (Table 2). A significant variability (standard deviation) was measured within each $0.5 \times 0.5 \mathrm{~m}^{2}$ pixel thanks to the TLS measurements: $0.031 \mathrm{~m}$ on average across the 8072 pixels. Secondly, we compared the interpolated snow-free surface elevations with the existing Digital Elevation Model of the ground. An average $0.003 \mathrm{~m}$ average elevation difference was measured between the GPS interpolated ground surface and the DEM data $\left(4044 \mathrm{~m}^{2}\right)$. The standard deviation of differences was $0.064 \mathrm{~m}$ (Table 2). Lastly, the GPS interpolated snow depth was compared with hand made measurements on several occasions (Table 2 and Appendix B). An average $-0.008 \mathrm{~m}$ average difference was measured between the GPS interpolated snow depth and the manual observations. The standard deviation of differences was $0.053 \mathrm{~m}$ (Table 2).

To sum up uncertainty analyses, the average difference in the snow surface elevation interpolated from the Differential GPS points with respect to either TLS measurements or DEM data, ranged between -0.012 and $0.003 \mathrm{~m}$ (Table 2) whilst the RMS of the differences ranged between 0.048 and $0.064 \mathrm{~m}$. The distribution should statistically not be considered as being normally distributed, though distributions are 
Table 2. Average difference and RMS of the differences between interpolated snow surface elevation and Terrestrial Laser Scan measurements on a snow pile (1 December 2015), between the elevation of bare ground with the GPS method and the existing Digital Elevation Model (DEM) and between interpolated snow depths and probe measurements on ski slopes (Appendix B).

\begin{tabular}{llrrr}
\hline Comparison method & Type/session & Number of points & $\begin{array}{r}\text { Average } \\
\text { difference }(\mathrm{m})\end{array}$ & $\begin{array}{r}\text { RMS of } \\
\text { differences }(\mathrm{m})\end{array}$ \\
\hline \multirow{2}{*}{ Terrestrial Laser Scan } & GPS points & 156 & -0.0046 & 0.055 \\
& Interpolated points & 8072 pixels $\left(2018 \mathrm{~m}^{2}\right)$ & -0.012 & 0.048 \\
\hline \multirow{2}{*}{ Digital Elevation Model } & GPS points & 145 & 0.032 & 0.047 \\
& Interpolated points & 16179 pixels $\left(4044 \mathrm{~m}^{2}\right)$ & 0.003 & 0.064 \\
\hline \multirow{5}{*}{ Probe manual measurements } & 13 & -0.002 & 0.041 \\
& 4 December 2015 & 8 & -0.019 & 0.046 \\
& 20 January 2016 & 8 & -0.006 & 0.073 \\
& 6 April 2016 & 29 & -0.008 & 0.053 \\
\hline
\end{tabular}

close in both cases to normality (Appendix B). Beyond these results we compared the interpolated snow depth with hand made measurements. The agreement was excellent (average error of $-0.008 \mathrm{~m}, \mathrm{RMSD}=0.053 \mathrm{~m}$ ) and a statistically significant test for normality (Table 2, Appendix B). Regarding the internal variability of the snow surface elevation within a pixel $(0.031 \mathrm{~m})$ and the sensitivity of the snow depth to the study area, we therefore considered $\sigma_{\mathrm{SA}}=0.03 \mathrm{~m}$ as the uncertainty concerning the elevation of the snow surface. We also considered the error on the snow surface elevation to be normally distributed, which was a reasonable approximation. Consequently the combined uncertainties on the elevations of snow surfaces $\left(\sigma_{\mathrm{SA}}\right)$ to obtain the snow depth uncertainty $\sigma_{\mathrm{SD}}$ can be deduced (Bevington and Robinson, 2003) assuming errors to be uncorrelated and providing a consistent value to the calculated RMS of the differences with the comparison methods (Table 2):

$\sigma_{\mathrm{SD}}=\sqrt{2} \cdot \sigma_{\mathrm{SA}}=0.042 \mathrm{~m}$.

\subsection{Conversion of snow volumes into snow masses}

The snow density was measured in several distinct locations on MM snow piles using a dedicated snow sampler $(1 / 2 \mathrm{~L})$ and by weighing the snow samples. We used the average density and standard deviation of all observations for the sessions when we could not perform density measurements (23 November and 1 December 2015). The uncertainty on MM snow density $\sigma_{\rho}$ for single snowmaking events was defined as the standard deviation of all density measurements (Table 3). The density showed a weak variation of $4 \%$ on MM snow density (Table 3 ) from one production session to another. This supported the assumption that one use the average and standard deviation of density across all observations regardless of the dates when measurements were missing.

We also performed measurements of the average density of the snowpack on the ski slope using a PICO coring auger (Koci and Kuivinen, 1984) for each session of observations. The snowpack average density on the ski slope showed a sig-
Table 3. Average MM snow density for each session of observations (top) and average snowpack density observed on the ski slope for all three sessions (bottom).

\begin{tabular}{lccc}
$\begin{array}{l}\text { Date of } \\
\text { observation }\end{array}$ & $\begin{array}{c}\text { Number of } \\
\text { measurements }\end{array}$ & $\begin{array}{c}\text { Average } \\
\text { density } \\
\left(\rho_{\mathrm{av}}, \mathrm{kg} \mathrm{m}^{-3}\right)\end{array}$ & $\begin{array}{c}\text { Standard } \\
\text { deviation } \\
\left(\sigma_{\rho}, \mathrm{kg} \mathrm{m}^{-3}\right)\end{array}$ \\
\hline \multicolumn{4}{c}{$\begin{array}{c}\text { Average density on MM snow piles } \\
\text { (prior to any action by grooming machines) }\end{array}$} \\
\hline All sessions & 21 & 437 & 18 \\
\hline \multicolumn{4}{c}{ Average density on the ski slope (as opened to skiers) } \\
\hline $\begin{array}{l}\text { 4 December 2015 } \\
\text { 20 January 2016 }\end{array}$ & 13 & 545 & 31 \\
6 April 2016 & 8 & 528 & 37 \\
\hline
\end{tabular}

nificant increase during the season. The uncertainty on the snowpack density was defined as the variability (standard deviation) of all density measurements for each single session (Table 3).

Whether on MM snow piles or on the ski slope, the Snow Water Equivalent (SWE, $\mathrm{kg} \mathrm{m}^{-2}$ ) was computed for each point of the grid by the Eq. (2) between snow depth and density:

$\mathrm{SWE}_{\mathrm{pt}}=\mathrm{SD}_{\mathrm{pt}} \cdot \rho_{\mathrm{av}}$.

The uncertainty on the SWE is computed assuming that the uncertainties on the snow depth $\left(\sigma_{\mathrm{SD}}\right)$ and density $\left(\sigma_{\rho}\right)$ are independent and normally distributed (Bevington and Robinson, 2003). The uncertainty on snow depth and density are considered to be $\pm \sigma$ therefore with a standard confidence interval of $68 \%$ (Bevington and Robinson, 2003).

$$
\left(\frac{\sigma_{\mathrm{SWE}}}{\mathrm{SWE}_{\mathrm{av}}}\right)^{2}=\left(\frac{\sigma_{\mathrm{SD}}}{\mathrm{SD}_{\mathrm{av}}}\right)^{2}+\left(\frac{\sigma_{\rho}}{\rho_{\mathrm{av}}}\right)^{2}
$$

The uncertainty $\sigma_{\mathrm{SWE}}$ is obtained for each session thanks to the the averages $\mathrm{SWE}_{\mathrm{av}}$ and $\mathrm{SD}_{\mathrm{av}}$ of the session by the 
Eq. (3). The resulting uncertainties $\sigma_{\mathrm{SWE}}$ ranged between $20 \mathrm{~kg} \mathrm{~m}^{-2}$ for MM snow observations and up to $35 \mathrm{~kg} \mathrm{~m}^{-2}$ on ski slopes.

\subsection{Modelling of snowpack conditions on ski slope}

Crocus Resort is an adapted version of the multilayer physically based snowpack model SURFEX/ISBA-Crocus (Vionnet et al., 2012). It explicitly takes into account the impact of grooming and snowmaking (Spandre et al., 2016b). Crocus Resort solves equations governing the energy and mass balance of the snowpack on the ski slope. The model time step is $900 \mathrm{~s}(15 \mathrm{~min})$. All simulations in this paper with MM snow production include the impact of grooming on the snow. The snow management component Crocus-Resort of Crocus model (Spandre et al., 2016b) requires the setting of a series of grooming and snowmaking rules and thresholds. For grooming, we used the standard approach described in Spandre et al. (2016b). For snowmaking, Crocus-Resort can be driven either with a target production framework, or by using observed production time series as an input. In both cases, production is only possible below wet bulb temperature and wind speed thresholds, and the snowmaking efficiency, i.e. the mass of snow corresponding to the mass of liquid water used (formally equivalent to the WRR), can be specified. The default value is 1 (no water loss accounted for, see Spandre et al., 2016b). In French mountain regions, Crocus Resort is usually run using outputs of the meteorological downscaling and surface analysis tool SAFRAN (Durand et al., 1993).

SAFRAN operates on a geographical scale on meteorologically homogeneous mountain ranges (referred to as "massifs") within which meteorological conditions are assumed to depend only on elevation and slope aspects. All simulations in this paper are based on meteorological forcing data from SAFRAN corresponding to Les 2 Alpes site (elevation, slope angle and aspect). We specifically analysed the natural snow conditions provided by SAFRAN-Crocus Resort with in situ observations on a local scale from ski patrollers and Automatic Weather Stations (wind, snow/rain elevation limit, precipitation amount). If relevant we adjusted the SAFRAN meteorological forcing data (amount and snow/rain phase of precipitations) to local conditions for this site. The deposition rate of dry impurities on the snowpack surface was also adapted to match the natural melting rate at the end of the season (Brun et al., 1992; Dumont et al., 2012). We also took into account the surrounding slopes of each site and the consequent shading effects (Morin et al., 2012; Spandre et al., 2016b). Lastly, the wet-bulb temperature was computed from SAFRAN dry-air temperature and specific humidity using the formulation from Jensen et al. (1990) as described by Spandre et al. (2016b).

\section{5 efinition and computation of the water recovery rate}

The Water Recovery Rate (WRR) is defined as the mass balance between the initial mass of water used for production and the resulting mass of MM snow (Eq. 4). The WRR therefore ranges between 0 and 1, and can be expressed in \% and computed either for a MM snow pile prior to any action by grooming machines or for a ski slope snowpack such as that offered to skiers.

$\mathrm{WRR}=\frac{\text { Mass }_{\text {snow }}}{\text { Mass }_{\text {water }}}=\frac{\text { Mass }_{\text {snow }}}{\text { Mass }_{\text {water }}}=\frac{\mathrm{SWE}_{\mathrm{av}} \cdot \text { Surface }}{\text { Volume }_{\text {water }} \cdot \rho_{\text {water }}}$

The $\mathrm{SWE}_{\mathrm{av}}$ was computed as defined in Sect. 2.3. The surface is determined by the study area. Since we neglected the uncertainty on the volume of water used for snowmaking (Sect. 2.1), the uncertainty on the WRR is related to the uncertainty on the SWE (Eq. 5). $\sigma_{\text {SWE }}$ was computed as defined in Sect. 2.3.

$\sigma_{\mathrm{WRR}}=\sigma_{\mathrm{SWE}} \cdot \frac{\text { Surface }}{\text { Volume }_{\text {water }} \cdot \rho_{\text {water }}}$

We performed simulations of the ski slope conditions which took into account recorded production $(100 \%$ water mass, Table 7) and where there was no production $(0 \%$ i.e. groomed only snow). We ran additional simulations using water recovery rates values prescribed to Crocus Resort below 1 and computed the RMS of the differences between the simulations and the observations. We used distinct water recovery rates for the first (20 November-5 December 2015) and the two later periods, regarding the differences in production conditions (Table 7).

- We simulated snow conditions using water recovery rates from 100 to $30 \%$ with a step of $5 \%$ and compared the snow conditions (SWE, SD) with the observation on 4 December 2015. The simulations which provided conditions within the range of uncertainty of the observations were selected.

- From this initial step providing distinct potential snowpack conditions on 5 December 2015 we performed additional simulations over the second period of the season (after 5 December 2015) using various water recovery rates prescribed to Crocus Resort to determine the overall water recovery rate based on the minimum RMS of differences between simulations and observations.

\section{Results}

\subsection{Single snowmaking events}

\subsubsection{Observations}

Snow piles were usually not that far ahead of the snowgun with a significant MM snow depth at the bottom or even 


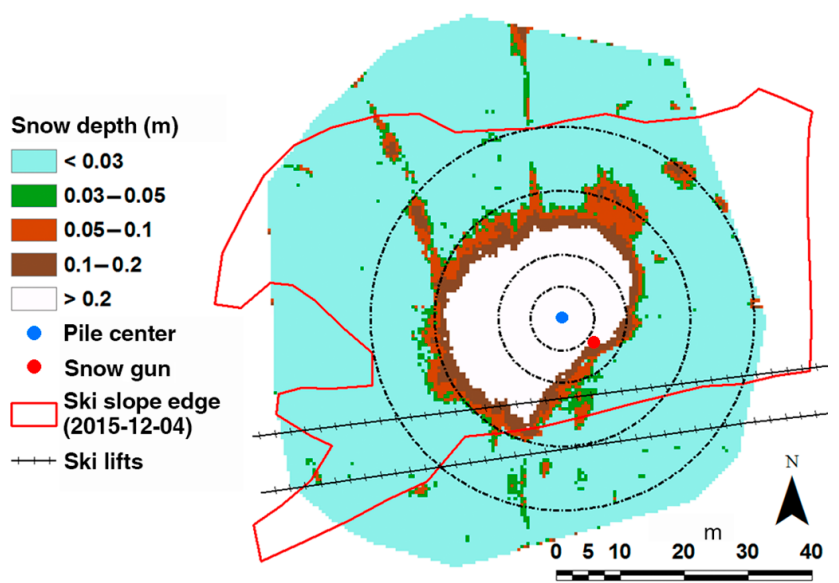

Figure 3. The snow depth raster for 23 November 2015 production session along with the positions of the snowgun, the center of the MM snow pile and the concentric circles of radius $R=5,10,20$ and $30 \mathrm{~m}$. The edge of the ski slope on 4 December 2015 is also shown.

at the back of it (Fig. 3) in consistency with the low wind speed conditions observed in all sessions (Table 4), mainly originating from the East or South-East on average (wind direction not shown). All observed snow piles showed similar geometric patterns (Figs. 3 and 4) resulting in consistent distributions of the snow around the center of the MM snow piles (Fig. 4). The uncertainty on the snow volume within a distance from the snowgun was computed as the product of the surface within the circle and the uncertainty on the snow depth (error bars in Fig. 4).

The average snow depth and the resulting snow volume were calculated for each session of MM snow production within concentric circles around a common fixed point. This point was defined from observations and named "center of MM snow pile" (identical for all sessions, Fig. 3). The equivalent water mass was calculated as the product of the average SWE within the considered circle (Eq. 2) and the surface of the disk inside the circle, providing the mass of water $(\mathrm{kg})$.

\subsubsection{Water recovery rate from observations of single snowmaking events}

The MM snow mass $(\mathrm{kg})$ was calculated for single sessions of production from the snow volumes $\left(\mathrm{m}^{3}\right)$ within concentric circles around the "center" point (Fig. 4) and the MM snow density $\left(\mathrm{kg} \mathrm{m}^{-3}\right.$, Table 3$)$. The MM snow mass was further divided by the mass of water used for MM snow production for the given session (Fig. 2, Table 4), providing the water recovery rate (WRR, \%, Fig. 5). The uncertainty on the snow mass within a distance from the snowgun was computed as defined in Sect. 2.3 and divided by the mass of water used for MM snow production for the given session to provide an uncertainty on the WRR ( $\sigma$ in \%, error bars in Fig. 5).

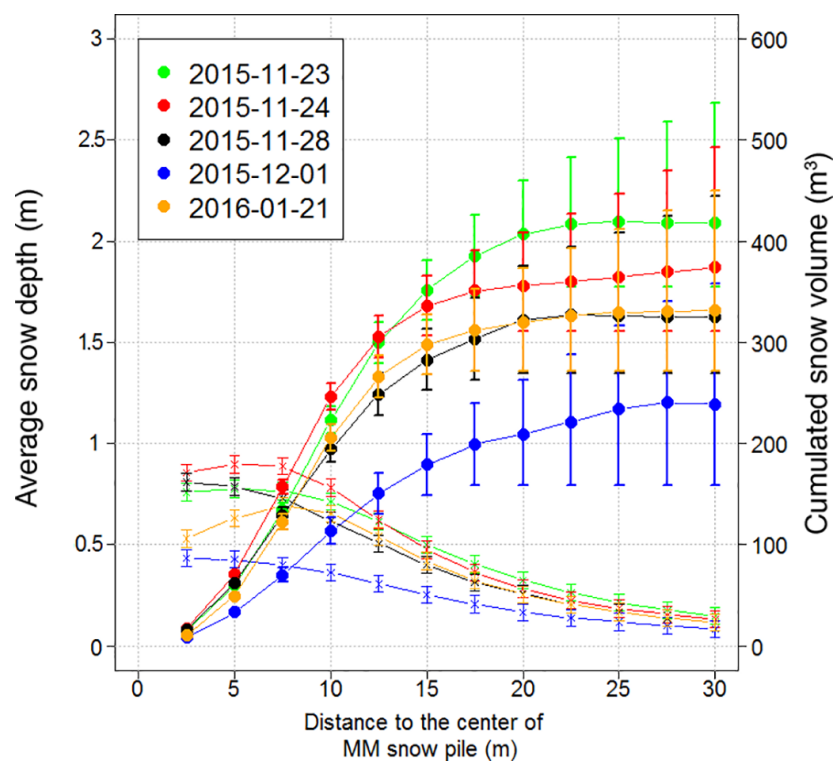

Figure 4. Average snow depth $(\mathrm{x})$ and cumulative snow volume $(\bullet)$ within concentric circles around the center of the MM snow pile of radius $R$ from 2.5 to $30 \mathrm{~m}$. The larger the circle the lower the average snow depth and thus the larger the uncertainty on the snow volume.

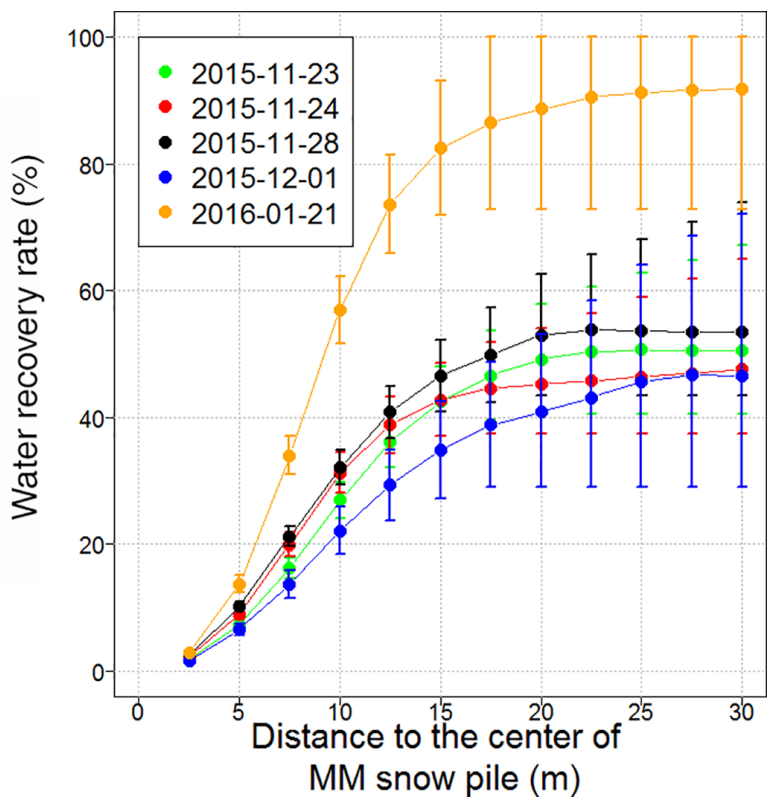

Figure 5. The water recovery rate $(\%)$ within concentric circles around the center of the MM snow pile. The larger the circle the larger the uncertainty on the snow volume and therefore the larger the uncertainty on the water recovery rate.

Beyond a distance of 20 to $25 \mathrm{~m}$ from the center of the snow pile, the MM snow volume no longer increases whereas the uncertainty is considerable (over $10 \%$, Fig. 5). This prevents any conclusion in relation to the recovery rate including 
Table 4. Detailed production conditions for every session, with the average value in bold $( \pm \sigma)$.

\begin{tabular}{lrrrrr}
\hline Session & 23 November 2015 & 24 November 2015 & 28 November 2015 & 1 December 2015 & 21 January 2016 \\
\hline Water flow $\left(\mathrm{m}^{3} \mathrm{~h}^{-1}\right)$ & $\mathbf{1 8 . 4}( \pm 1.7)$ & $\mathbf{1 8 . 2}( \pm 1.7)$ & $\mathbf{1 7 . 1}( \pm 1.7)$ & $\mathbf{1 3 . 1}( \pm 1.7)$ & $\mathbf{1 2 . 4}( \pm 1.7)$ \\
\hline Production duration $(\mathrm{h})$ & 19.6 & 19.2 & 15.8 & 17.3 & 12.0 \\
\hline $\begin{array}{l}\text { Wet-bulb temperature }\left({ }^{\circ} \mathrm{C}\right) \\
\text { Wind speed }\left(\mathrm{m} \mathrm{s}^{-1}\right)\end{array}$ & $\mathbf{- 8 . 1}( \pm 1.5)$ & $\mathbf{- 8 . 7}( \pm 1.1)$ & $\mathbf{- 8 . 5}( \pm 1.4)$ & $\mathbf{- 7 . 5 ( \pm 1 . 1 )}$ & $\mathbf{- 7 . 8}( \pm 1.7)$ \\
\hline $\begin{array}{l}\text { Recorded water volume } \\
\begin{array}{l}\text { used for snowmaking } \\
\left(\mathrm{m}^{3}\right)\end{array}\end{array}$ & $\mathbf{1 . 8 2}( \pm 0.8)$ & $\mathbf{1 . 0 6}( \pm 0.48)$ & $\mathbf{0 . 5 3}( \pm 0.53)$ & $\mathbf{0 . 5 6}( \pm 0.47)$ & $\mathbf{0 . 5 3}( \pm 0.58)$ \\
\hline
\end{tabular}

Table 5. The water recovery rate within $10 \mathrm{~m} / 20 \mathrm{~m}$ (average value in bold $\pm \sigma$ ) around the center of the MM snow pile.

\begin{tabular}{ccccccr}
\hline Session & & $2015-11-23$ & $2015-11-24$ & $2015-11-28$ & $2015-12-01$ & $2016-01-21$ \\
\hline \multirow{2}{*}{ Water recovery rate $(\%)$} & $R=10 \mathrm{~m}$ & $\mathbf{2 6 . 9}( \pm 2.8)$ & $\mathbf{3 1 . 3}( \pm 3.2)$ & $\mathbf{3 2 . 0}( \pm 2.7)$ & $\mathbf{2 2 . 1}( \pm 3.7)$ & $\mathbf{5 6 . 9}( \pm 5.3)$ \\
& $R=20 \mathrm{~m}$ & $\mathbf{4 9 . 2}( \pm 8.6)$ & $\mathbf{4 5 . 2}( \pm 8.8)$ & $\mathbf{5 3 . 0}( \pm 9.6)$ & $\mathbf{4 0 . 8}( \pm 12.4)$ & $\mathbf{8 8 . 7}( \pm 11.4)$ \\
\hline
\end{tabular}

Table 6. Performance of the snowpack model in simulating the natural snow conditions before and after the adjusting of the meteorological forcing data and impurities rate (Sect. 2.4) quantified by the RMS of differences between model and observations.

\begin{tabular}{lcccc}
\hline Natural snow & \multicolumn{3}{c}{ RMS differences } & Melt-out date \\
\cline { 2 - 4 } & $\begin{array}{c}\text { SWE } \\
\left(\mathrm{kg} \mathrm{m}^{-2}\right)\end{array}$ & $\begin{array}{c}\text { SD } \\
(\mathrm{m})\end{array}$ & $\begin{array}{c}\text { Density } \\
\left(\mathrm{kg} \mathrm{m}^{-3}\right)\end{array}$ & \\
\hline Observations & \multicolumn{3}{c}{$N=6$ observations } & 1 April 2016 \\
SAFRAN - Crocus & 51 & 0.21 & 82 & 6 April 2016 \\
Adjusted SAFRAN - Crocus & 14 & 0.14 & 22 & 2 April 2016 \\
\hline
\end{tabular}

those areas. All sessions before the resort opened showed an approximate 20 to $30 \%$ water recovery rate within $10 \mathrm{~m}$ and 40 to $50 \%$ within $20 \mathrm{~m}$ (Table 5). The 21 January 2016 session showed similar behavior with significantly higher WRR (57 and $89 \%$ within respectively 10 and $20 \mathrm{~m}$ distances). Such differences are discussed further in Sect. 4.

\subsection{Seasonal snow accumulation}

\subsubsection{Performance of the model in simulating natural snow conditions and wet-bulb temperatures}

The computation of the uncertainty on the natural snow water equivalent was based on the simulation results with and without correction of the forcing data and impurities rate (Sect. 2.4). The RMS of the differences between the simulations and the in situ observations are highly reduced (improved simulations) when fitting the meteorological forcing data to the specificities of the site (Table 6). The final RMS of the differences on SWE (after corrections) is $14 \mathrm{~kg} \mathrm{~m}^{-2}$ and final errors on the snow depth, SWE and density are similar to Essery et al. (2013), confirming that SAFRANCrocus provides realistic simulations of the natural snow- pack evolution once adjustments are made in albedo (impurities) and forcing data. We therefore assumed that the SAFRAN-Crocus Resort model would also provide realistic simulations of the groomed snowpack. We accounted for a larger uncertainty on the snow water equivalent of the groomed snowpack $\left(\sigma_{\mathrm{SWE}}=30 \mathrm{~kg} \mathrm{~m}^{-2}\right.$ i.e. $0.06 \mathrm{~m}$ uncertainty on snow depth for a $500 \mathrm{~kg} \mathrm{~m}^{-3}$ density, Spandre et al. (2016b)).

Apart from the natural snow conditions, the cumulated time-span over which wet-bulb temperature fell within specific ranges was calculated for the MM snow production period i.e. from 20 November 2015 until 15 March 2016, both from the in situ data recorded by the snowgun sensor and the data from SAFRAN (Fig. 6). The distribution of the wetbulb temperature from SAFRAN meteorological data is very consistent with the $T_{\mathrm{w}}$ distribution from the snowgun sensor.

\subsubsection{Snowmaking data}

The production period was divided in the model into three distinct periods: before and after the resort opened (5 December 2015) and after 1 February 2016, the reasons being that the average conditions significantly differ (Table 7) and the 
Table 7. Observed production conditions for the main periods of production before and after the resort opened.

\begin{tabular}{lrrrrrr}
\hline Period & $\begin{array}{r}\text { Total } \\
\text { volume } \\
\left(\mathrm{m}^{3}\right)\end{array}$ & $\begin{array}{r}\text { Average } \\
\text { Water flow } \\
\left(\mathrm{m}^{3} \mathrm{~h}^{-1}\right)\end{array}$ & $\begin{array}{r}\text { Average } \\
T_{\mathrm{w}} \\
(\mathrm{oC})\end{array}$ & $\begin{array}{r}\text { Production } \\
\text { Surface } \\
\left(\mathrm{m}^{2}\right)\end{array}$ & $\begin{array}{r}\text { MM Snow } \\
\text { Precipitation rate } \\
\left(\mathrm{kg} \mathrm{m}^{-2} \mathrm{~s}^{-1}\right)\end{array}$ & $\begin{array}{r}T_{\mathrm{W}} \\
\text { threshold } \\
\left({ }^{\circ} \mathrm{C}\right)\end{array}$ \\
\hline 21 November-5 December & 1629 & 16.2 & -9.5 & 4063 & $1.11 \times 10^{-3}$ & -3.5 \\
5 December-1 February & 657 & 10.2 & -6.7 & 6632 & $4.27 \times 10^{-4}$ & -5 \\
1 February-1 April & 661 & 11.1 & -6.9 & 7067 & $4.36 \times 10^{-4}$ & -5 \\
\hline
\end{tabular}

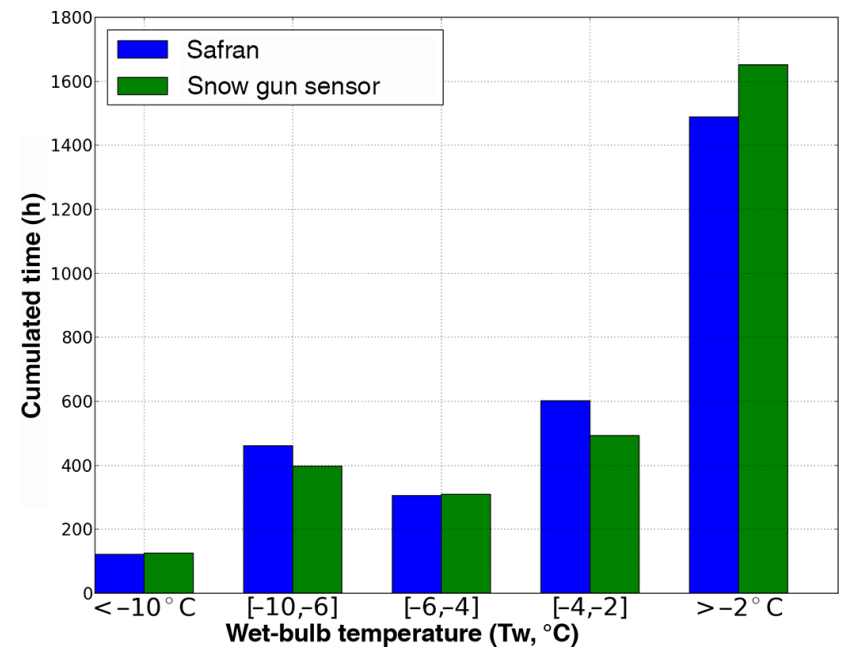

Figure 6. Cumulated time-span over which wet-bulb temperature fell within specific ranges, from the in situ data (snowgun sensor) and SAFRAN (20 November 2015-15 March 2016).

ski slope surface opened to skiers was significantly enlarged as the season progressed, modifying the usable surface of the ski slope.

As a result, we used the water flow recorded by snowmakers and the observed ski slope surface area (Table 7) to force the MM snow precipitation rate in the model which is constant for each period (expressed in $\mathrm{kg} \mathrm{m}^{-2} \mathrm{~s}^{-1}$ ). The daily production time was set in the model to match the observed daily production (expressed in $\mathrm{kg} \mathrm{m}^{-2}$, Fig. 2). A wet-bulb temperature threshold of $-3.5^{\circ} \mathrm{C}$ was found to be the minimum temperature for the triggering of snowmaking which afforded the production of the observed amount of MM snow during the first period (21 November-5 December). Afterwards, the observed MM snow production could be simulated using a triggering temperature of $-5^{\circ} \mathrm{C}$.

\subsubsection{Observations and modelling of the seasonal snow accumulation}

The variability of the snow depth (Fig. 7) and thus of the associated snow water equivalent (SWE) on the ski slope was significant. The variability (standard deviation) of the SWE values in the study area showed a factor from 3 to 4 with the
Table 8. The average $S W E$ observed on the ski slope ( $\left.S W E_{a v}\right)$ along with the standard deviation of the raster values within the study area (Fig. 7$)$ and the uncertainty $\left(\sigma_{\mathrm{SWE}}\right)$ resulting from the computation in Sect. 2.3.

\begin{tabular}{lrrr}
\hline $\begin{array}{l}\text { Date of } \\
\text { observation }\end{array}$ & \multicolumn{3}{c}{$\begin{array}{c}\text { Snow water equivalent } \\
\left(\mathrm{kg} \mathrm{m}^{-2}\right)\end{array}$} \\
\cline { 2 - 4 } & $\begin{array}{r}\text { Average } \\
\text { SWE }_{\mathrm{av}}\end{array}$ & $\begin{array}{r}\text { Spatial variability } \\
\text { (standard deviation) }\end{array}$ & $\begin{array}{r}\text { Uncertainty } \\
\sigma_{\text {SWE }}\end{array}$ \\
\hline 4 December 2015 & 278 & 87 & 28 \\
20 January 2016 & 393 & 111 & 35 \\
6 April 2016 & 501 & 120 & 33 \\
\hline
\end{tabular}

uncertainty $\sigma_{\mathrm{SWE}}$ (Sect. 2.3, Table 8). Two major observations can be made from the distribution of the snow depth on the ski slope (Fig. 7):

- the shape of the MM snow piles was not completely erased by the grooming machines. The maximum values of snow depth surrounded the center of the MM snow piles in December and January and was slightly further in April. This may be due to the slow erosion of the snow towards the bottom of the slope by skiers, despite the work made by the grooming machines;

- the initial distribution of the MM snow on the "useful area" defined on 4 December 2015 could still be noticed on the two latest dates (e.g. the northern and southern edge).

The average SWE difference between the simulation accounting for MM snow and the observations was $172 \mathrm{~kg} \mathrm{~m}^{-2}$ $\left(\mathrm{RMSD}=204 \mathrm{~kg} \mathrm{~m}^{-2}\right)$ whilst between the simulation of groomed snow (no production) and the observations the average difference was $-239 \mathrm{~kg} \mathrm{~m}^{-2}\left(\mathrm{RMSD}=282 \mathrm{~kg} \mathrm{~m}^{-2}\right)$. On the three observation dates, neither of the two simulations provided conditions (SD, SWE) within the range of uncertainty of observations. Even though accounting for MM snow production significantly improved the simulation, the differences with observations remained high and suggested the actual amount of MM snow stood between these two simulations.

Based on the observations and the simulations of the natural and groomed snowpacks, we calculated the number of days when the snowpack equivalent water mass exceeded 


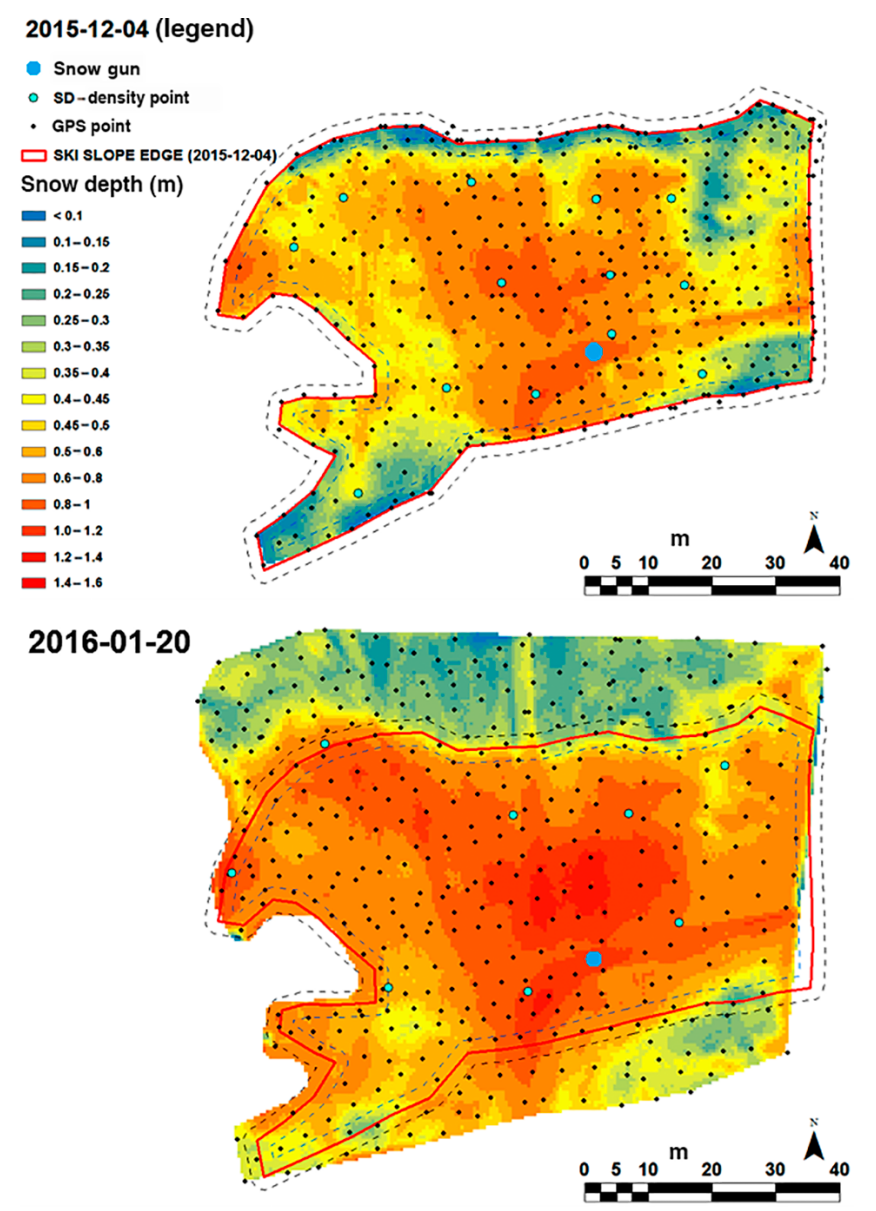

2016-04-06

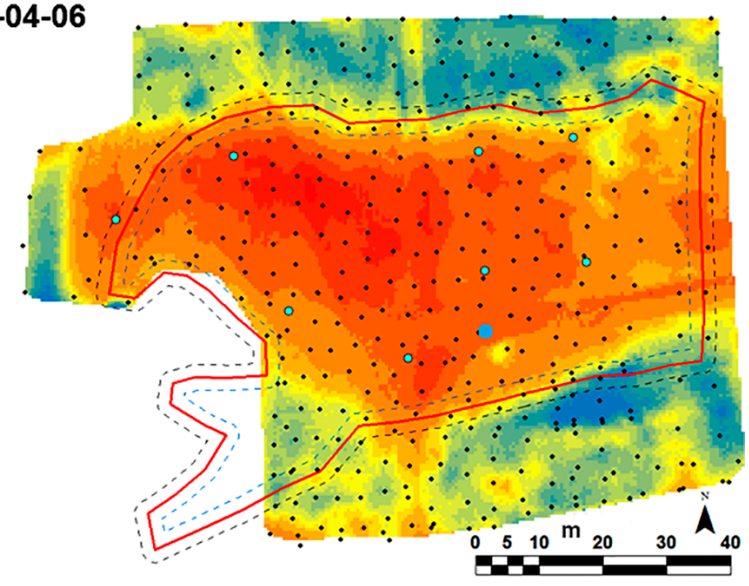

Figure 7. Snow depth mapping for the three observation dates 4 December 2015 (top), 20 January 2016 (center) and 6 April 2016 (bottom). See Appendix A for details on the location of the observation site.

thresholds of 1 and $80 \mathrm{~kg} \mathrm{~m}^{-2}$ i.e. respectively the number of days with snow on the ground (Töglhofer et al., 2011) and with suitable conditions for skiing (a minimum of $20 \mathrm{~cm}$ of snow with a density of $400 \mathrm{~kg} \mathrm{~m}^{-3}$, Marke et al., 2014). The following number of days were calculated:
- Concerning the natural snow, the ground was covered by snow for 107 days and the SWE exceeded $80 \mathrm{~kg} \mathrm{~m}^{-2}$ for 48 days of the season.

- Concerning the groomed snowpack (no production), the ground was covered by snow for 133 days and the SWE exceeded $80 \mathrm{~kg} \mathrm{~m}^{-2}$ for 82 days of the season.

- Concerning the ski slope (grooming plus snowmaking), the ground was covered by snow for 165 days and the SWE exceeded $80 \mathrm{~kg} \mathrm{~m}^{-2}$ for 159 days of the season (estimated from the observed melt-out date and the melting rate between 6 April and 3 May 2016).

In Les 2 Alpes ski resort, the ski season lasted from 5 December 2015 until 30 April 2016 i.e. 148 days. The days when the ground was covered by either natural or groomed snow were not consecutive: the snow melted entirely in late December and there was no snow during the Christmas holidays in both cases. Even though grooming significantly lengthened the snow cover period, the length of the season with suitable skiing conditions was far shorter than the period open to skiers ( 82 instead of 148 days). The production of MM snow therefore achieved the objective for the provision of consecutive days with snow on the ground, ensuring suitable conditions for skiing during the Christmas holidays and a sufficiently long skiing season.

\subsection{Water recovery rate from observations and simulations of the seasonal snow accumulation}

The MM snow mass was calculated as the difference between the observed total mass of snow within the edge of the ski slope and the mass of natural snow from the simulated groomed snowpack (Sect. 3.2.1). The MM snow mass was further divided by the cumulated mass of water used for MM snow production up until the date of observations (Fig. 2, Table 7), providing the water recovery rate (Table 9). Note that this calculation is based on each date on the total surface of the marked ski slope. This means that a significant part of the early production (before 5 December 2015) may have fallen beyond the edge of the ski slope when opened to skiers on 4 December 2015 but within the edge of the ski slope when opened to skiers on 20 January 2016 (or 6 April 2016). This may partially explain the higher recovery rate on 20 January and 6 April 2016 compared to 4 December 2015 (Table 9).

Considering the first period of production (20 November5 December 2015), the simulations provided conditions within the range of uncertainty of the observation for water recovery rates of 65, 60 (minimum RMS of differences) and $55 \%$ (Table 10). From this initial step providing three potential snowpack conditions on 5 December 2015 (Fig. 8), we performed twelve simulations across the second period of the season (after 5 December 2015) using four distinct water recovery rates of $100,65,55$ and $45 \%$. Of these twelve simulations, three provided results within the range of un- 
Table 9. Water recovery rate (Average value in bold $\pm \sigma$ ) from observations of the snow mass difference between ski slope snow conditions and simulated groomed snowpack conditions (i.e. without snowmaking).

\begin{tabular}{lrrrr}
\hline Date & $\begin{array}{r}\text { Ski slope surface } \\
\left(\mathrm{m}^{2}\right)\end{array}$ & $\begin{array}{r}\text { Cumulated water mass } \\
\text { for production }(\mathrm{kg})\end{array}$ & $\begin{array}{r}\text { Observed mass difference } \\
(\mathrm{kg})\end{array}$ & $\begin{array}{r}\text { Water recovery rate } \\
(\%)\end{array}$ \\
\hline 4 December 2015 & 4063 & $1629 \times 10^{3}$ & $974 \times 10^{3}\left( \pm 167 \times 10^{3}\right)$ & $\mathbf{5 9 . 8}( \pm 10.2)$ \\
20 January 2016 & 6632 & $2286 \times 10^{3}$ & $1551 \times 10^{3}\left( \pm 306 \times 10^{3}\right)$ & $\mathbf{6 7 . 9}( \pm 13.4)$ \\
6 April 2016 & 7067 & $2947 \times 10^{3}$ & $1896 \times 10^{3}\left( \pm 315 \times 10^{3}\right)$ & $\mathbf{6 4 . 3}( \pm 10.7)$ \\
\hline
\end{tabular}

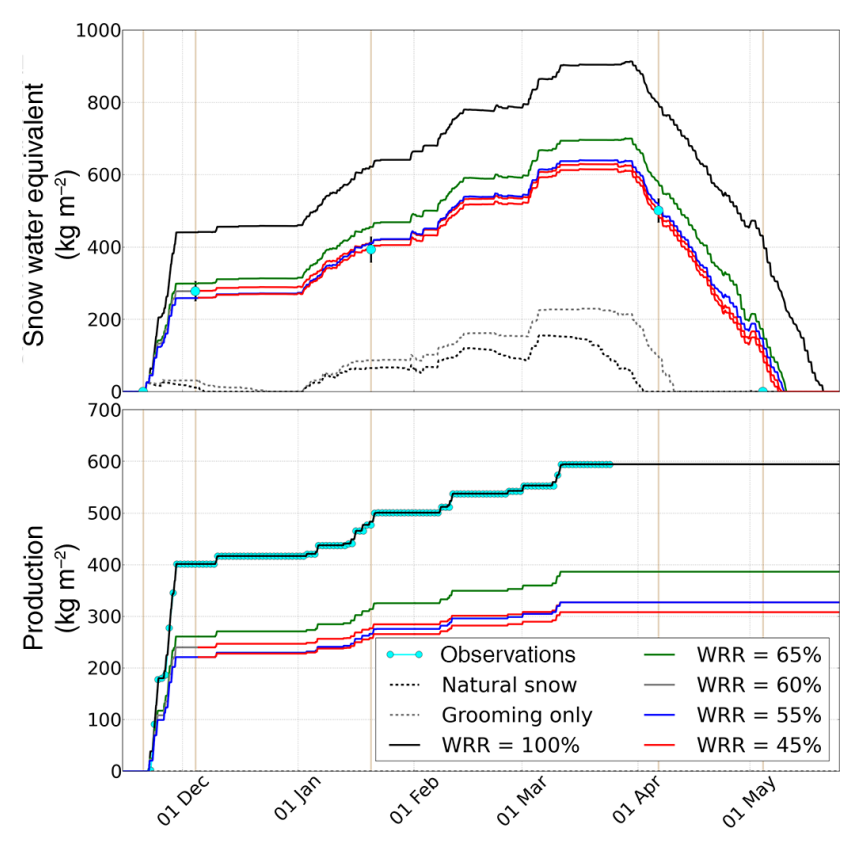

Figure 8. Seasonal evolution of the ski slope snowpack. Simulations of natural snow and groomed natural snow conditions are shown along with simulations of the ski slope conditions including MM snow production, accounting for water recovery rates (WRR) of $100 \%, 65 \%$ and the three combinations (Table 10) which provided the best agreement with the observations (dots with error bars).

certainty for all three dates of observations ( $n=3$, Table 10) along with the minimum RMS of differences on the SWE $\left(10-20 \mathrm{~kg} \mathrm{~m}^{-2}\right)$. Detailed results can be found in Table 10 .

These results suggest that 55 to $65 \%$ of the total water mass used for production can be recovered as MM snow within the edge of the ski slope during the first period. This is consistent with the water recovery rates calculated in Sect. 3.1.1. The sensitivity test on the water recovery rate did not show any significant difference between the first period of production compared to later in the season. The water recovery rate may even be slightly lower with 45 to $55 \%$ of the SWE observed on the ski slope.

The season duration was computed from simulations similar to Sect. 3.2.3 for the three combinations of water recovery rates providing the best agreement with observations (Ta- ble 10). The ground was covered by snow for 170 to 171 days and the SWE exceeded $80 \mathrm{~kg} \mathrm{~m}^{-2}$ for 164 to 166 days during the season, which is consistent with the observed lengths (Sect. 3.2.3). The bias on the ski season duration and total melt-out date is attributed to a lower melting rate in the snow model compared to observations: an average -15.8 to $-16.2 \mathrm{~kg} \mathrm{~m}^{-2} \mathrm{day}^{-1}$ for the simulations using the three combinations of water recovery rates (Table 10) with respect to $-17.8 \mathrm{~kg} \mathrm{~m}^{-2} \mathrm{day}^{-1}$ for the observations from 1 April 2016 to the total melt-out date.

The interest in both the professional (technical issues, investments) and research (climate change investigations) approaches of the production of snow lies in the consideration of the amount of "useful" additional MM snow that can be used on the ski slope. Any difference between the mass of water used for production and the additional snow mass on the ski slope can be considered as water loss in the mass balance. Such losses may be due either to the evaporation and sublimation of water droplets or snow particles (thermodynamic effects). They may also be due to the produced snow falling beyond the edge of the ski slope (mechanical effects). We intend in the following sections to address the impacts of such effects.

\section{Discussions}

\subsection{Water losses due to thermodynamic effects (evaporation and sublimation)}

Losses related to evaporation and sublimation can be calculated for the sake of the present study thanks to the linear relationship proposed by Eisel et al. (1988). Although significant changes in snowguns technology have occurred in the last 30 years, this work remains at present the most detailed on this topic to the best of our knowledge. We might also consider this approach as a "worst case" scenario since the technological evolution has presumably evolved positively since, for better efficiency. The observed average temperatures of production were respectively $-9.5,-6.7$, and $-6.9^{\circ} \mathrm{C}$ for the first, second and third periods of production (Table 7), resulting in respectively $5.84,7.9$, and $7.7 \%$ water losses due to water vapor evaporation from droplets and sublimation of ice particles, both during and after their deposition on the ground (Eisel et al., 1988). The overall water loss over 
Table 10. Performance of the snowpack model in simulating ski slope snow conditions. $n$ is defined as the number of simulations found within the range of uncertainty for the observation dates. The RMS of the differences between the simulations and the observations are detailed for the 100 and $65 \%$ water recovery rate (WRR) simulations, for the three combinations of WRR which provided the best agreement with the observations (Fig. 8) and for the simulation of the groomed snowpack (no production, WRR=0\%). Period 1 extends from 20 November until 5 December 2015. Periods 2 and 3 extend from 5 December 2015 until the melt-out date.

\begin{tabular}{|c|c|c|c|c|c|c|}
\hline \multicolumn{3}{|c|}{ Water recovery rate $|n|$} & \multicolumn{3}{|c|}{ RMS difference } & Melt-out date \\
\hline \multicolumn{2}{|c|}{ Period } & & \multirow{2}{*}{$\begin{array}{r}\text { SWE } \\
\left(\mathrm{kg} \mathrm{m}^{-2}\right)\end{array}$} & \multirow{2}{*}{$\begin{array}{l}\text { SD } \\
(\mathrm{m})\end{array}$} & \multirow{2}{*}{$\begin{array}{r}\text { Density } \\
\left(\mathrm{kg} \mathrm{m}^{-3}\right)\end{array}$} & \\
\hline 1 & 2 and 3 & & & & & \\
\hline \multicolumn{2}{|c|}{ Observations } & \multicolumn{4}{|c|}{$N=3$ observations } & 3 Мау 2016 \\
\hline $0 \%$ & $0 \%$ & 0 & 282 & 0.5 & 189 & 10 April 2016 \\
\hline $100 \%$ & $100 \%$ & 0 & 204 & 0.28 & 50 & 15 Мау 2016 \\
\hline $65 \%$ & $65 \%$ & 1 & 51 & 0.03 & 51 & 10 May 2016 \\
\hline $60 \%$ & $45 \%$ & 3 & 9 & 0.05 & 63 & 9 May 2016 \\
\hline $55 \%$ & $55 \%$ & 3 & 15 & 0.04 & 54 & 9 Мау 2016 \\
\hline $55 \%$ & $45 \%$ & 3 & 11 & 0.07 & 62 & 8 May 2016 \\
\hline
\end{tabular}

the total $2947 \mathrm{~m}^{3}$ used for snowmaking would be $6.7 \pm 3 \%$ (Eisel et al., 1988), i.e. well below the observed differences in the present study. Evaporation and sublimation processes may explain to some extent the differences reported by either Eisel et al. (1990), Olefs et al. (2010), Spandre et al. (2016b) or those observed in the present study. An overall water loss of $40 \%( \pm 10 \%)$ was observed and simulated, in which less than $10 \%$ may be due to thermodynamic effects according to Eisel et al. (1988). This results in an additional mechanical water loss of approximately $30 \%$ of the total water mass used for MM snow production. The influence of external factors (topography, wind) proves a major concern for water loss.

\subsection{Water losses due to mechanical effects}

Although the wind conditions were ideal, a significant amount of snow was found at the toe or even at the back of the snowgun (Sect. 3.1.1). Wind drift of already deposited MM snow was very unlikely due to both the density and the cohesion of snow grains (capillarity/refrozen water). Since snowguns are usually installed on one side of the ski slope, a part of the production may fall outside the slope, behind the snowgun. The MM snow may also fall beyond the edge of the slope on the opposite side of the snowgun. Hanzer et al. (2014) performed a detailed study of technical snow in an Austrian ski area with $37 \mathrm{~km}$ of ski slopes for a total surface of 92 ha i.e. average ski slopes of $25 \mathrm{~m}$ in width. Spandre et al. (2016a) reported similar data from a survey of French ski resorts with average ski slope widths of $20 \mathrm{~m}$. The width of a ski slope may have a significant impact on the amount of MM snow falling within the edge of the ski slope in terms of the equivalent water masses of MM snow piles within 10 to $20 \mathrm{~m}$ from the center point (Table 4). These results also suggest that the best position of a snowgun is, if possible, in the middle of the ski slope (as is already the case in certain situations).
The surroundings of the ski slope are very important for the computing of the amount of "useful" MM snow. If the slope can be enlarged (as is the case for Les 2 Alpes Coolidge slope), the MM snow falling outside the initial edge of the ski slope can either be displaced by grooming machines or used for the extension of the slope. In the opposite case where the surroundings have complex topography (e.g. rough surfaces, with rocks) or are covered by vegetation (trees), the amount of snow falling beyond the edge of the ski slope is definitively lost. Consequently the potential for the extension of a ski slope is a significant factor for differences in MM snow efficiency between slopes (or even resorts). As a focus for this point, the study site may not be representative of the majority of ski slopes. The Coolidge slope is wider (it has a minimum width of $45 \mathrm{~m}$, and a maximum of $75 \mathrm{~m}$ ) than the ski slopes with average dimensions that have been referred to (Hanzer et al., 2014; Spandre et al., 2016a). This makes it a favourable site for the efficiency of MM snow: a maximum amount of the produced snow can be found within the edge of the slope. The total mass of water used for MM snow production also exceeds usual amounts: Spandre et al. (2016a) found that the usual capacity of water reservoirs was $150-190 \mathrm{~kg}$ of water per $\mathrm{m}^{2}$ for an equipped ski slope with snowmaking facilities with a maximum of $390 \mathrm{~kg} \mathrm{~m}^{-2}$. In the present case, $2947 \mathrm{~m}^{3}$ of water were used for snowmaking (Table 7) across a maximum ski slope surface of $7067 \mathrm{~m}^{2}$ (Sect. 2.1) i.e. $417 \mathrm{~kg} \mathrm{~m}^{-2}$.

The influence of meteorological conditions on the efficiency of MM snow remains unknown to a great extent and requires further observation in order to be analysed, in light of the findings from Eisel et al. (1988). Meteorological conditions observed in this study appeared ideal for the production of MM snow: low wind speed and temperatures (Table 4). Such investigations may prove useful for operational purposes in providing objective data on the impact of producing snow in extreme conditions of wind or temperature. 
The "Quality" parameter of MM snow chosen by professional snowmakers may also have a significant impact on the water recovery rate (Tables 4 and 5, Figure 5). The sessions concerning 21 January 2016 and 1 December 2015 differ mainly due to the parameterization of the "Quality" with significant differences in the WRR. To the best of our knowledge this parameter acts on the volume of compressed air versus water volumes within the cloud expelled by the snowgun. There are objective reasons why this parameter has a significant impact on the water recovery rate. Higher air/water ratio leads to a lower specific humidity in the cloud of droplets and thus a lower gradient with the surrounding ambient air. This likely leads to decreasing latent heat exchanges (evaporation and sublimation) and increasing sensible heat transfer i.e. further freezing due to a higher surface for heat transfer between liquid water and air. Lastly, a lower water flow means a lower speed for droplets when they are expelled by the snowgun. There is then a higher probability that they fall within the edge of the ski slope. To provide an example, on 28 November 2015 the water mass used for production was $275 \times 10^{3} \mathrm{~kg}$, leading to $159 \times 10^{3} \mathrm{~kg}$ of snow $(\mathrm{WRR}=53 \%$, Tables 4 and 5). On 21 January 2016 , the water mass was $152 \times 10^{3} \mathrm{~kg}$ whilst the snow mass was $135 \times 10^{3} \mathrm{~kg}(\mathrm{WRR}=89 \%)$. The water mass used on 28 November 2015 was 1.8 times higher than that of 21 January 2016 which had only 1.08 times more in terms of snow mass. Further investigations are required to improve our understanding of the impact of this parameter and to confirm its influence.

\subsection{Limitations of this work: assessment of water recovery rates and current modelling of ski slope snowpacks}

The MM snow mass within the edge of the ski slope was computed from observations (Sects. 3.2.3 and 3.3) or simulations (Sect. 3.3) and compared with the recorded mass of water used for production. These computations provided consistent values of the water recovery rate for the first period of production (before 5 December 2015) with $60 \%$ of the total water mass used for production within the edge of the ski slope open to skiers. Afterwards, the observations of the total mass of snow showed a higher WRR when accounting for the total surface of the ski slope (Sect. 3.3) compared with calculations with the surface limited to the edge of the ski slope on 4 December 2015 (Sect. 3.3). This suggests that a part of the initial production may have fallen beyond the initial edge of the ski slope. This higher WRR could also be due to an improved recovery of individual productions after 5 December 2015 as suggested by the observations on the MM snow pile on 21 January 2016. Simulations performed from the initial conditions of the snowpack on 4 December 2015 suggest however that the WRR is lower for the subsequent period than for the first. Several factors may explain these differences in the WRR. They could either be related both to objective factors not accounted for and to some weaknesses of the method. We intend hereafter to address such factors:

- The representativity of observations may be questioned. The observations of MM snow piles (Sect. 3.1.1) covered $75 \%$ of the total mass of water used for production during the first period (1214 out of $1629 \mathrm{~m}^{3}$ ) while they covered only $11 \%$ of the production after 5 December 2015 (152 out of $1318 \mathrm{~m}^{3}$ ). The observation on 21 January 2016 may not be representative of the whole period of production after 4 December 2015.

- The difficulty in monitoring human action on the ski slope (e.g. snow displacement by grooming machines) is a potential source of error. The distribution of snow on 6 April 2016 (Fig. 7) suggests that there was a significant volume of snow displaced from the study area (within the 4 December 2015 edge) to the North-West corner of the ski slope (6 April 2016). Such displacements of snow may explain why the observed snow mass within the initial edge (4 December 2015) did not increase in the second period of production as we expected from initial snow conditions and further MM snow productions (after 4 December 2015).

- Thirdly, the snowpack evolution highlights strong nonlinear thermal behavior (Armstrong and Brun, 2008) the effect of which might be significant for this study. In one case the natural and groomed snowpacks in December completely melted, in the other the simulations accounting for the production of MM snow did not show a significant loss of equivalent water mass within the same period (Fig. 8). Consequently, the SWE of the groomed snowpack on 4 December 2015 might not be lost on the ski slope and should be subtracted when calculating the mass of MM snow (Sect. 3.3). If accounting for an additional $20 \mathrm{~kg} \mathrm{~m}^{-2}$ equivalent water mass on the 4 December 2015 snowpack, we obtain adjusted water recovery rates of respectively 62.1 and $59.5 \%$ for 20 January and 6 April 2016. These corrected WRR are closer to those computed for the first period $(59.8 \%$, Sect. 3.3) and would tend to confirm that there is no significant difference in the WRR between the first and the two latest periods of production.

- Lastly, complementary observations might have reduced the uncertainty across estimations of the equivalent water recovery rate (an observation was performed on 2 March 2016 but could not be treated due to a GPS failure lasting until early April). Since the calculation of the mass of MM snow (Sect. 3.3) depends on the snow water equivalent of the groomed snowpack, observations on ski slopes without production would have been of great help. Every slope in study site surroundings is, however, equipped with MM snow facilities or is under the influence of these facilities. Extra observations on MM snow piles after 5 December 2015 could 
have clarified whether or not the higher WRR observed on 21 January 2016 was representative of the period or not. Additional observations with different types of snowguns would also have been of interest, although the snowgun used at the observations site is the most sold air/water gun of a brand which manufactures approximately $80 \%$ of the snowmaking facilities in French ski resorts (communication from the manufacturer). It may therefore be considered as representative of the current technology.

One dimensional ( $z$-vertical) models feature several limitations for the simulation of ski slope conditions. These are highlighted in the present study through the bias on the total melt-out date related to lower melting rates of the simulations with respect to the observations.

- Firstly, the model can not account for snow/ground partitioning. The variability of the snow depth on the ski slope (Fig. 8, Sect. 3.2.3) showed there were horizontal heterogeneities of snow properties, either due to the mass transport by skiers or the partial spreading of MM snow piles by grooming engines. This is particularly obvious when the total melting of the natural (and even groomed) snowpack in December and April made the ski slope an isolated snow patch in a mostly snow-free area with strong edge-effects. In such a situation the energy balance of the snowpack can be significantly affected by the modification of turbulent fluxes (Essery et al., 2006) and horizontal ground fluxes from snow-free areas in the vicinity (Lejeune et al., 2007). Since snow free areas have lower albedo values than the snow and are not limited to a $0^{\circ} \mathrm{C}$ maximum temperature, they can become significantly warmer than the surrounding snow and advect heat to the snow through the air (and respectively the ground), providing additional sensible heat energy to the snowpack. These two effects of the snow ground partitioning would enhance the melting rate in the model if they were accounted for, which is not the case.

- Secondly, the initial content of impurities in MM snow may also differ from natural snow. The amount of impurities in a snow layer is based on Crocus in both an initial value of impurities (i.e. initial albedo) and a deposition rate of dry impurities on the snowpack (Brun et al., 1992). There is no reason for the dry deposition to show a difference between natural snow and the snow on ski slopes (at the same location). The initial amount of impurities in MM snow could differ however from that in natural snow: the water used for production is stored in open reservoirs and probably contains more impurities than snow can capture in the air during growth and precipitation. This could be a reason for a lower albedo of MM snow which would also enhance the melting rate on ski slopes.

\section{Conclusions}

The present study carried out detailed observations and simulations of snowmaking events and of the seasonal snow evolution of a ski slope snowpack in Les Deux Alpes ski resort (French Alps). The production of MM snow concentrated on the early season with approximately $50 \%$ of the seasonal production realized within one week in late November (Fig. 8). The production of MM snow significantly improved the possibility of skiing at the observation site with suitable conditions from the opening (5 December 2015) to the closing date of the resort (30 April 2016).

We provided spatial observations of the snow depth and snow water equivalent of MM snow piles and of the ski slope once it was opened to skiers. A high spatial resolution of the snow surface elevation was used $(0.5 \mathrm{~m}$ grid $)$ thanks to measurements by a Differential GPS method. The related uncertainties were computed with a final uncertainty of $0.042 \mathrm{~m}$ on snow depth. The density of snow was measured thanks to snow sampling and weighting, with uncertainties ranging between 4 and $7 \%$ (Sect. 2).

The mass balance between the MM snow mass and the water mass used for snowmaking was defined as the water recovery rate. The observations of snowmaking events showed similar distributions around the center of the MM snow pile with approximately $30 \%$ WRR within $10 \mathrm{~m}$ and $50 \%$ within $20 \mathrm{~m}$ for production sessions in the early season (Sect. 3.1.1). The water recovery rate within the ski slope edge was computed on three occasions with approximately $60 \%( \pm 10 \%)$ of the water mass used for snowmaking recovered as MM snow (Sects. 3.2.3 and 3.3). The WRR was found to be relatively constant between observations and simulations and between the different periods of the season. The water losses due to thermodynamic effects were calculated from Eisel et al. (1988) linear approximation with less than $10 \%$ of the total water mass either evaporated or sublimated (Sect. 4). Over $30 \%$ of the water used for snowmaking probably turned to MM snow therefore, but could not be recovered within the edge of the ski slope, certainly due to mechanical effects (suspension and erosion by the wind, obstacles, etc) while production conditions can be considered as ideal (low wind speed and temperatures, large ski slope).

The water recovery rate of the snowmaking process poses therefore a tricky question regarding its likely dependence to both sites' characteristics (topography, vegetation) and human decision (attention to marginal conditions, quality parameter, etc.). Estimating a single value appears to be impossible even though the best conditions together (as can be considered in the present study) showed that a significant fraction of the water used for production was lost for the ski slope. The water recovery rate would have an optimum value when the most favorable conditions occurred together. An objective one is definitely the local topography: less than $50 \%$ of the water mass can be expected within the edge of a typical ski slope width (approximately 20-30 m, Sect. 4.2) 
with snowguns on the side and perpendicular to the slope (a typical installation). The authors also hypothesize that the wind may have a strong impact on the distances covered by water droplets and ice particles as well as the quality parameter chosen by professional snowmakers (although further investigation of such influences is needed).

Characterizing the actual mass of MM snow that can be recovered on ski slopes from a given mass of water remains a major issue for ski resorts regarding the current development of snowmaking facilities (Spandre et al., 2015) and the related costs of investments and production (Damm et al., 2014). Significant water losses may question the economical interest of snowmaking for resorts where periods with suitable meteorological conditions are limited in addition to deteriorating factors for the efficiency of MM snow (obstacles e.g. trees, wind).

Data availability. The data used for this publication are available upon request from the authors. 
Appendix A: Situation of the observations site

(a)
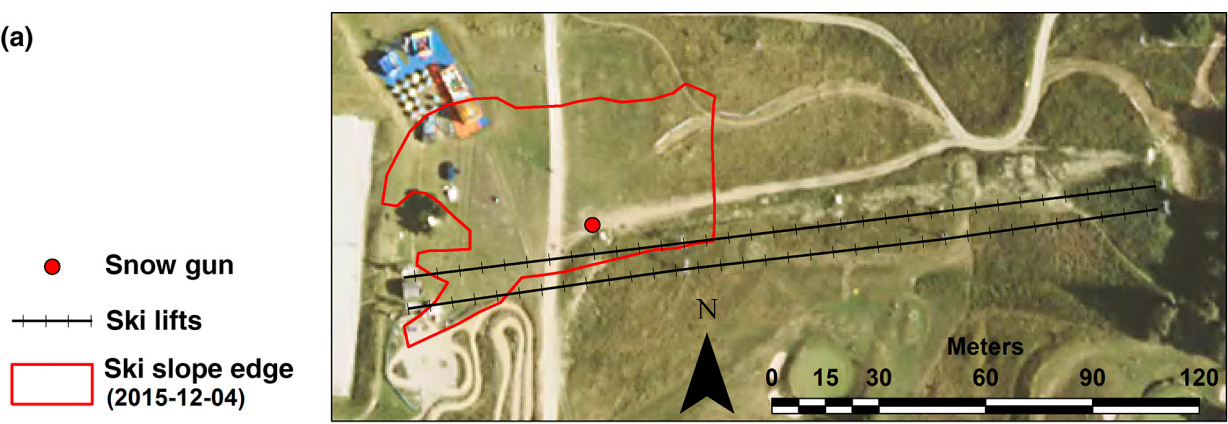

(b)

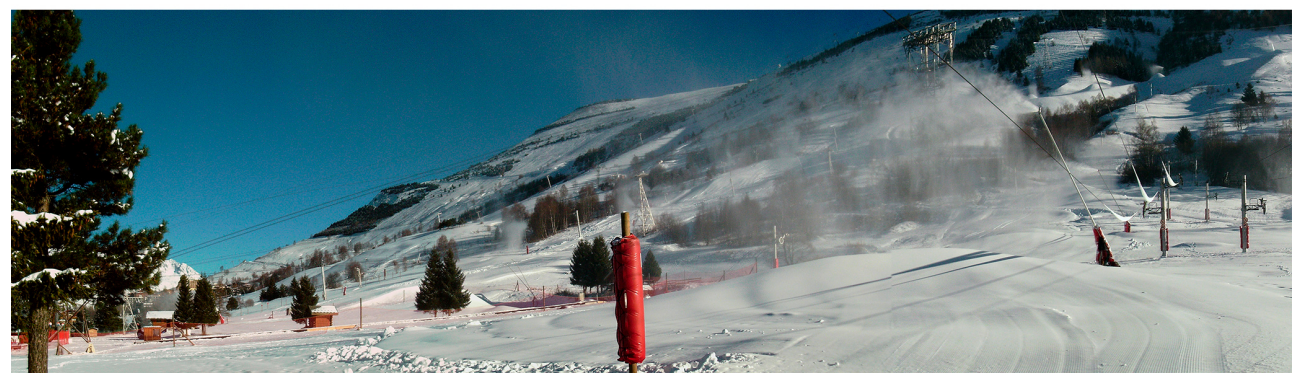

Figure A1. (a) Observations site from above. Temporary structures in the top left corner were not present during the winter season. (b) A picture of the production session on 27 November 2015. MM snow can be seen on the tree and on the cables of the ski lift. 


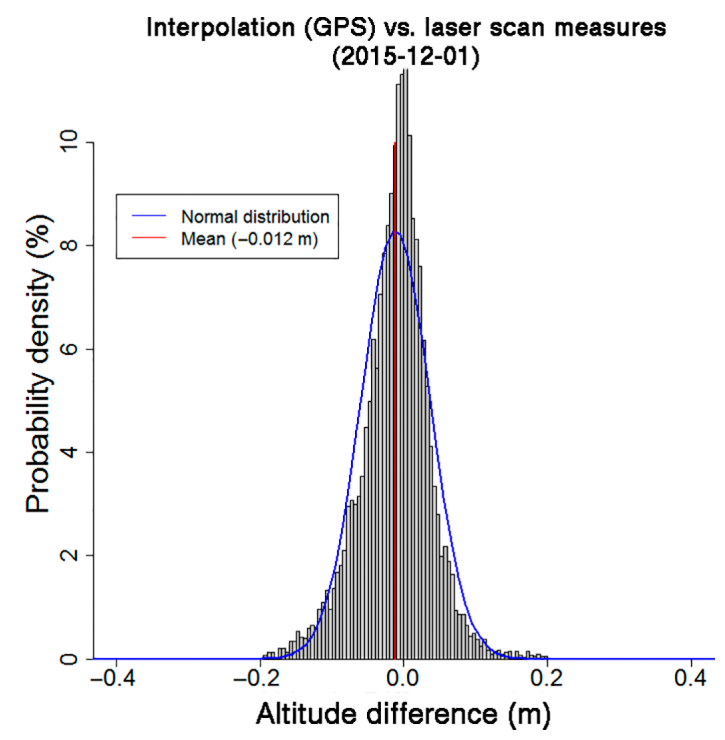

Figure B1. Probability density of the elevation differences between the interpolated snow surface and the TLS snow surface on 1 December 2015.

\section{Appendix B: Evaluation of uncertainties on snow depth}

We used an Optech Ilris-LR laser scanner thewavelength of which $(1064 \mathrm{~nm})$ is adapted to the low reflectance of the snow in the infra-red spectrum. The laser scan point cloud was adjusted on targets the coordinates of which were determined thanks to a total station. The internal consistency of the target network was $\pm 0.0038 \mathrm{~m}$ and its relative positioning with respect to the GPS reference station was $0.008 \mathrm{~m}$ in planimetry and $0.013 \mathrm{~m}$ in elevation. We conducted Shapiro-Wilk tests for normality (Royston, 1982) over samples of 5000 differences between interpolated elevations and the TLS measurements (see below the average results). All tests suggest that the differences on snow surface elevation should not be considered as normally distributed even though the distribution is coherent with a normal distribution (Fig. B1).

- Statistical value $w=0.979$

- $p$ value $=1.48 \times 10^{-25}(<0.05)$

Secondly, we compared the interpolated snow-free surface elevations from the existing Digital Elevation Model of the ground. We conducted once more Shapiro-Wilk normality tests (Royston, 1982) over samples of 5000 differences between interpolated ground elevations and the Digital Elevation Model data (see below the average results). All tests suggest that the differences should not be considered as normally distributed even though the distribution appears to be very consistent with normality (Fig. B1).

- Statistical value $w=0.951$

- $p$ value $=1.59 \times 10^{-34}(<0.05)$

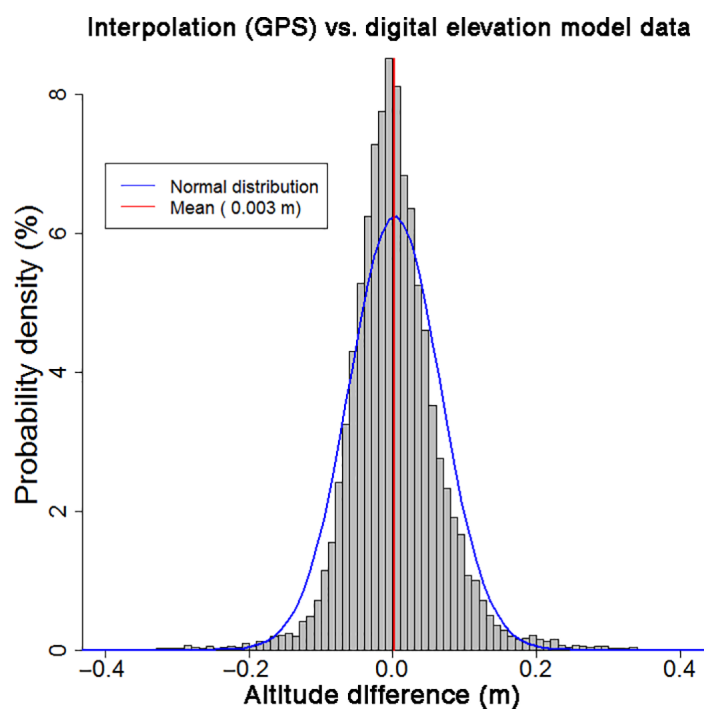

Figure B2. Probability density of the elevation differences between the interpolated bare ground surface and the Digital Elevation Model ground surface.

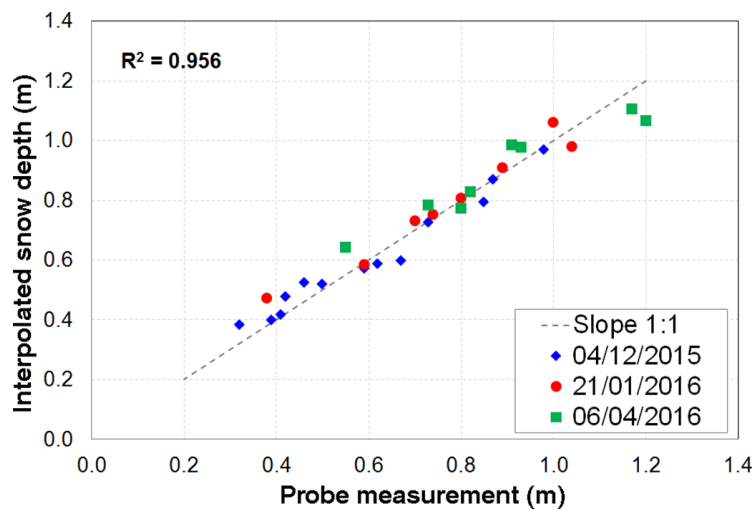

Figure B3. Interpolated snow depth from GPS method with respect to the hand made probe measurements for each observations session of ski slope. Average difference and RMS of the differences are detailed in Table 2 .

Lastly, the GPS interpolated snow depth was compared with hand made measurements on several occasions (Table 2, Fig. B3). We conducted a Shapiro-Wilk normality test (Royston, 1982) to ascertain the differences between interpolated snow depth and the manual measurements (see below). This suggests that the differences on snow depth are normally distributed:

- Statistical value $w=0.963$

- $p$ value $=0.38(>0.05)$ 
Competing interests. The authors declare that they have no conflict of interest.

Acknowledgements. The authors thank Fabian Wolsfperger and two additional anonymous reviewers for their helpful comments and suggestions. The authors also wish to thank A. Guerrand (Les Deux Alpes Loisirs) for sharing all details about the management of snow in Les Deux Alpes ski resort, the IGE (Institut des Géosciences de l'Environnement, Grenoble, France) for provision of the PICO coring auger (D. Six). We also acknowledge the assistance of F. Ousset (Irstea), Y. Deliot and G. Guyomarc'h in the set up and analysis of field observations, M.Dumont in the parameterization of impurities in Crocus as well as A. Dufour, L. Queno, L. Charrois and J. Revuelto in the fulfillment of observations (all CNRM/CEN). The Région Rhônes-Alpes funded Pierre Spandre's $\mathrm{PhD}$ through ARC Environment. This work has been supported by a grant from "Eau, Neige et Glace" foundation, from the LabEx OSUG@2020 (Investissements d'avenir - ANR10LABX56), and fundings from SO/SOERE GLACIOCLIM, IGE, IRSTEA, and CNRM/CEN.

Edited by: R. Brown

Reviewed by: F. Wolfsperger and two anonymous referees

\section{References}

Armstrong, R. and Brun, E.: Snow and climate: physical processes, surface energy exchange and modeling, Polar Res., 29, 461-462, doi:10.3402/polar.v29i3.6091, 2008.

Bergstrom, K. and Ekeland, A.: Effect of trail design and grooming on the incidence of injuries at alpine ski areas, Brit. J. Sport. Med., 38, 264-268, doi:10.1136/bjsm.2002.000270, 2004.

Bevington, P. R. and Robinson, D. K.: Data reduction and error analysis, McGraw-Hill, 3rd Edn., available at: http://experimentationlab.berkeley.edu/sites/default/files/pdfs/ Bevington.pdf (last access: 4 April 2017), 2003.

Brun, E., David, P., Sudul, M., and Brunot, G.: A numerical model to simulate snow-cover stratigraphy for operational avalanche forecasting, J. Glaciol., 38, 13-22, 1992.

Damm, A., Koeberl, J., and Prettenthaler, F.: Does artificial snow production pay under future climate conditions? - A case study for a vulnerable ski area in Austria, Tourism Manage., 43, 8-21, doi:10.1016/j.tourman.2014.01.009, 2014.

Dumont, M., Durand, Y., Arnaud, Y., and Six, D.: Variational assimilation of albedo in a snowpack model and reconstruction of the spatial mass-balance distribution of an alpine glacier, J. Glaciol., 58, 151-164, 2012.

Durand, Y., Brun, E., Mérindol, L., Guyomarc'h, G., Lesaffre, B., and Martin, E.: A meteorological estimation of relevant parameters for snow models, Ann. Glaciol., 18, 65-71, 1993.

Durand, Y., Giraud, G., Laternser, M., Etchevers, P., Mérindol, L., and Lesaffre, B.: Reanalysis of 47 Years of Climate in the French Alps (1958-2005): Climatology and Trends for Snow Cover, J. Appl. Meteorol. Clim., 48, 2487-2512, doi:10.1175/2009JAMC1810.1, 2009.

Eisel, L. M., Mills, K. D., and Leaf, C. F.: Estimated consumptive loss from man made snow, JAWRA Journal of the American
Water Resources Association, 24, 815-820, doi:10.1111/j.17521688.1988.tb00932.x, 1988.

Eisel, L. M., Mills, K. D., and Leaf, C. F.: Estimated runoff from man made snow, JAWRA Journal of the American Water Resources Association, 26, 519-526, doi:10.1111/j.17521688.1990.tb01390.x, 1990.

Essery, R., Granger, R., and Pomeroy, J.: Boundary-layer growth and advection of heat over snow and soil patches: modelling and parameterization, Hydrol. Process., 20, 953-967, doi:10.1002/hyp.6122, 2006.

Essery, R., Morin, S., Lejeune, Y., and Menard, C. B.: A comparison of 1701 snow models using observations from an alpine site, Adv. Water Resour., 55, 131-148, doi:10.1016/j.advwatres.2012.07.013, 2013.

Fauve, M., Rhyner, H., Schneebeli, M., Schneebeli, M., and Schneebeli, M.: Preparation and maintenance of pistes: handbook for practitioners, Swiss Federal Institute for Snow and Avalanche Research, Davos, SLF, available at: http://www.wsl.ch/eshop/ product_info.php?cPath=39_41\&products_id=152 (last access: 4 April 2017), 2002.

Fierz, C., Armstrong, R. L., Durand, Y., Etchevers, P., Greene, E., McClung, D. M., Nishimura, K., Satyawali, P. K., and Sokratov, S. A.: The International Classification for Seasonal Snow on the Ground, IHP-VII, Technical Documents in Hydrology no. 83, IACS Contribution no. 1, available at: http://unesdoc.unesco.org/ images/0018/001864/186462e.pdf (last access: 4 April 2017), 2009.

Hanzer, F., Marke, T., and Strasser, U.: Distributed, explicit modeling of technical snow production for a ski area in the Schladming region (Austrian Alps), Cold Reg. Sci. Technol., 108, 113-124, doi:10.1016/j.coldregions.2014.08.003, 2014.

Hennessy, K., Whetton, P., Walsh, K., Smith, I., Bathols, J., Hutchinson, M., and Sharples, J.: Climate change effects on snow conditions in mainland Australia and adaptation at ski resorts through snowmaking, Climate Res., 35, 255-270, doi:10.3354/cr00706, 2007.

Hopkins, D.: The perceived risks of local climate change in Queenstown, New Zealand, Current Issues in Tourism, 18, 947-965, doi:10.1080/13683500.2013.776022, 2015.

Hopkins, D. and Maclean, K.: Climate change perceptions and responses in Scotland's ski industry, Tourism Geogr., 16, 400-414, doi:10.1080/14616688.2013.823457, 2014.

Hughes, M. G. and Robinson, D. A.: Historical snow cover variability in the Great Plains region of the USA: 1910 through to 1993, Int. J. Climatol., 16, 1005-1018, doi:10.1002/(SICI)10970088(199609)16:9<1005::AID-JOC63>3.0.CO;2-0, 1996.

Jensen, M. E., Burman, R. D., and Allen, R. G.: Evapotranspiration and irrigation water requirements, American Society of Civil Engineers, National Leader, Colorado Institute for Irrigation Management (CIIM), Ft. Collins, CO, available at: http: //cedb.asce.org/cgi/WWWdisplay.cgi?67841 (last access: 4 April 2017), 1990.

Koci, B. R. and Kuivinen, K. C.: The PICO lightweight coring auger, J. Glaciol., 30, 244-245, 1984.

Lejeune, Y., Wagnon, P., Bouilloud, L., Chevallier, P., Etchevers, P., Martin, E., Sicart, E., and Habets, F.: Melting of snow cover in a tropical mountain environment in Bolivia : Processes and modeling, J. Hydrometeorol., 8, 922-937, doi:10.1175/JHM590.1, 2007. 
Marke, T., Strasser, U., Hanzer, F., Stötter, J., Wilcke, R. A. I., and Gobiet, A.: Scenarios of future snow conditions in Styria (Austrian Alps), J. Hydrometeorol., 16, 261-277, doi:10.1175/JHMD-14-0035.1, 2014.

Maune, D. F.: Digital elevation model technologies and applications: the DEM users manual, 2nd Edn., American Society For Photogrammetry and Remote Sensing (ASPRS), Bethesda, MD, ISBN: 1570830827, 2007.

Morin, S., Lejeune, Y., Lesaffre, B., Panel, J.-M., Poncet, D., David, P., and Sudul, M.: An 18-yr long (1993-2011) snow and meteorological dataset from a mid-altitude mountain site (Col de Porte, France, $1325 \mathrm{~m}$ alt.) for driving and evaluating snowpack models, Earth Syst. Sci. Data, 4, 13-21, doi:10.5194/essd-4-13-2012, 2012.

Morrison, C. and Pickering, C.: Perceptions of the ski tourism industry and others to impacts, adaptation and limits to adaption to climate change in the Australian Alps, J. Sustain. Tour., 21, 173-191, doi:10.1080/09669582.2012.681789, 2012.

Olefs, M., Fischer, A., and Lang, J.: Boundary Conditions for Artificial Snow Production in the Austrian Alps., J. Appl. Meteorol. Clim., 49, 1096-1113, doi:10.1175/2010JAMC2251.1, 2010.

Prokop, A.: Assessing the applicability of terrestrial laser scanning for spatial snow depth measurements, Cold Reg. Sci. Technol., 54, 155-163, doi:10.1016/j.coldregions.2008.07.002, 2008.

Pütz, M., Gallati, D., Kytzia, S., and Elsasser, H.: Winter tourism, climate change, and snowmaking in the Swiss Alps: tourists attitudes and regional economic impacts, Mt. Res. Dev., 31, 357362, doi:10.1659/MRD-JOURNAL-D-11-00039.1, 2011.

Royston, J.: Algorithm AS 181: the W test for normality, J. Roy. Stat. Soc. C-App., 31, 176-180, doi:10.2307/2347986, 1982.
Scott, D., McBoyle, G., and Mills, B.: Climate change and the skiing industry in Southern Ontario (Canada): exploring the importance of snowmaking as a technical adaptation, Climate Res., 23, 171-181, doi:10.3354/cr023171, 2003.

Spandre, P., François, H., Morin, S., and George-Marcelpoil, E.: Snowmaking in the French Alps. Climatic context, existing facilities and outlook, Journal of Alpine Research|Revue de géographie alpine, 103-2, 17 pp., doi:10.4000/rga.2913, 2015.

Spandre, P., François, H., George-Marcelpoil, E., and Morin, S.: Panel based assessment of snow management operations in French ski resorts, Journal of Outdoor Recreation and Tourism, 16, 24-36, doi:10.1016/j.jort.2016.09.002, 2016a.

Spandre, P., Morin, S., Lafaysse, M., George-Marcelpoil, E., François, H., and Lejeune, Y.: Integration of snow management in a detailed snowpack model, Cold Reg. Sci. Technol., 125, 4864, doi:10.1016/j.coldregions.2016.01.002, 2016b.

Steiger, R.: The impact of climate change on ski season length and snowmaking requirements in Tyrol, Austria, Climate Res., 43, 251-262, doi:10.3354/cr00941, 2010.

Töglhofer, C., Eigner, F., and Prettenthaler, F.: Impacts of snow conditions on tourism demand in Austrian ski areas, Climate Res. 46, 1-14, doi:10.3354/cr00939, 2011.

Trawöger, L.: Convinced, ambivalent or annoyed: Tyrolean ski tourism stakeholders and their perceptions of climate change, Tourism Manage., 40, 338-351, doi:10.1016/j.tourman.2013.07.010, 2014.

Vionnet, V., Brun, E., Morin, S., Boone, A., Faroux, S., Le Moigne, P., Martin, E., and Willemet, J.-M.: The detailed snowpack scheme Crocus and its implementation in SURFEX v7.2, Geosci. Model Dev., 5, 773-791, doi:10.5194/gmd-5-773-2012, 2012. 